\title{
An Empirical Investigation of Citizens' Preferences Among Four Energy Scenarios
}

\author{
O. RENN, H.U. STEGELMANN, G. ALBRECHT, U. KOTTE, H.P. PETERS
}

\begin{abstract}
Within the context of the Jülich Compatibility Study on Energy Supply Systems the model of the planning cell was used to incorporate participation into the process of policy formulation and evaluation and to gain information about intuitive preferences conceming the four basic energy scenarios constructed by the Enquete Commission of the German Federal Parliament. Planning Cells consist of groups of citizens who are selected by random process and are given paid leave from their workday obligations for a limited period of time to work out solutions for social problems. A total of 24 planning cells were organized throughout Germany to evaluate the four energy scenarios and to formulate recommendations for the policy maker. As a result most citizens favored the more moderate scenarios $[1,5]$, but were almost equally divided in their preference distribution with respect to the pronuclear (option 2) and non-nuclear scenario (option 3). Using a simplified MAU-model to determine the preferences of each citizen, the surprising result was achieved that more than $40 \%$ of the participants reached the highest positive score for the most antinuclear, soft energy scenario. This result could be partly explained by cognitive factors and by preference group influence.
\end{abstract}

\section{Introduction}

How can polarized social conflict involving risk be reduced and replaced by an atmosphere of trust and mutual respect among the opposing parties? What research is needed to design an environment in which effective multiway communication, constructive debate, and compromise can take place? [7]

This quote taken from a list of 10 relevant research questions in the field of risk and technology assessment refers to one of the most promising and demanded, but at the same time most ambitious, tasks of social science research: the promotion of social

ORTWIN RENN is currently a research associate of the Nuclear Research centre in Jülich, head of the research department "Man and Technology" within the program group "Technology and Society," and lecturer of the University of Stuttgart.

HANS-ULRICH STEGELMANN, formerly a mathematician at the Technical University of Aachen, is currently with the program group "Technology and Society" of the Nuclear Research Centre in Jülich.

GABRIELE ALBRECHT is currently a social scientist with the program group "Technology and Society" of the Nuclear Research Centre in Jülich.

ULRICH KOTTE was formerly employed by a subsidiary company of the Stiftung Volkswagenwerk and the International Atomic Energy Agency in Vienna, and is currently working at the Nuclear Research Centre in Jülich, especially on the problems of information transfer in the energy field for the program group "Technology and Society."

HANS PETER PETERS is currently a social scientist with the program group "Technology and Society" of the Nuclear Research Centre in Jülich.

Address reprint requests to Dr. Ortwin Renn, Program Group: Technology and Society, Nuclear Research Centre, P. O. Box 1913, D-5170 Jülich-1, F. R. Germany. 
integration. This task is based on the assumption that science cannot only provide data for clarifying relationships between given phenomena, but could also offer procedural advice on how to resolve conflicts. But can science, and in particular social science, contribute to conflict management? Is science the appropriate instrument to interfere into the political debate and to facilitate the formation of compromises? Is the role of science overstressed by aiming towards a mediating function between social interest groups?

Most subsystems of society perceive themselves as central agents for the wellfunctioning of society in general. They consider their contribution an essential effort to support the present coherence of social forces and a decisive means to shape the future performance of society. The sub-system of science might also overstate its social influence by demanding a superior position as an arbiter in social conflict.

What kinds of services can science offer to the policy-maker in order to facilitate conflict resolution? There are basically four possible contributions of utilizing scientific expertise for political consulting.

1. Disclusion of false inferences: Using the methods of scientific inquiry it is possible, at least in principle, to investigate the likelihood of various consequences of proposed policy actions and to exclude factual statements that can be proven wrong.

2. Modeling of causal structures: Since reality is characterized by a high degree of complexity, any policy maker is unable to overlook the consequences of his political action. With the aid of an abstract model, a scientist can create a simplified picture of causal interdependencies which provides some insights into the probable consequences of policy options.

3. Forecasting of future developments and consequences: In addition to causal relationships between policy actions and social consequences, scientists can describe the direction and probability of technological and social change by combining data from past experiences and revealing general trends of social and economic development. They might also provide information by which means politically desirable states of society can be achieved.

4. Providing arenas for conflict resolutions: Scientists can propose procedures and formal methods of how to facilitate conflict management. The process of decision making can be designed in such a way that the affected interest groups perceive a fair chance to participate in the final decision-making process and that the general public can gain the feeling that their concerns have been taken seriously. Such a mediating role of science can only be accomplished if the arena is being shaped by scientists without interfering into the arbitration process by means of their own values and preferences [5].

These four principle contributions of science to policy making have been challenged by the actual performance of scientific expertise in the political arena. Experts themselves are bound into the network of social interest and act often as advocates of policies or ideologies. Also, the separation between values and facts (which underlie the cooperative function of policy makers and scientists, respectively) is rather artificial and dubious. As a result, either the scientists come up with only those facts that support their own preferences (technocratic planning) or the politicians use factual expertise merely as a justification of preformulated political decisions. Interest groups are more interested in scientists as advocates (of their own case) and less interested in scientists as mediators. By utilizing scientific expertise to legitimize one's own claims it is more probable to gain 
a higher proportion of social influence. It can also be expected that one-sided scientific support reinforces the motivation and mobilization of all group members (a vital interest for survival, if the interest group is not yet institutionalized). Only when groups involved in the conflict realize that polarization does not help any one of them to proceed and when factual paralysis of policy making has taken place, scientists might be called in to initiate a first move.

Overlooking the past experience of policy consulting, the results are rather discouraging: even simple facts are disputed among scientists; models are constructed to back-up one's own political point of view; the scope of forecasting ranges from predicting extinction of all life on earth to a coming age of paradise, and no one seems to show any interest in the integrative role that science is able to play. A German official of the Federal Ministry for Research and Technology recently stated: "We knew in advance what was right or wrong. But since we faced public opposition, we spent millions of dollars for scientific consulting. But what we got is even a bigger mess. Now we are in real trouble!" Instead of reconciliation a lot of conflicts in society were aggravated by engaging scientists as consultants.

There is no easy way out! On one hand, we have to realize that the potential of scientific expertise has not been utilized in a proper way; on the other hand, we observe an increasing demand for scientific expertise in the policy-making process. There are four basic reasons for our increased need for such scientific evaluation:

1. Modern industrial societies have developed such a high level of complexity that merely "guessing" remains as the only viable alternative to scientific inquiry. Common sense or political experience are not sufficient anymore to foresee the consequences of political actions.

2. Modern industrial societies are characterized by a high degree of interdependencies between economic, social, and political parameters, resulting in a high sensitivity of the system for minor changes. Policy actions in one field might affect the outcomes of a completely different social segment. This requires more scientific research and advice.

3. Because of the high degree of industrialization (connected with overpopulation), the potentials of modern technologies, and the interaction between political decision making and the physical and social environment, the magnitude of possible outcomes has reached a level at which global catastrophes can be caused by human activities. Ecological collapse, atomic war, famine, or systems breakdown are the most serious problems in the modern world. Since major political decisions might create irreversible consequences that make such catastrophes more probable, scientific advice is of vital interest for any social system to have access to at least a rough scientific estimation of the magnitude of consequences that are connected with one or the other policy option.

4. As the public in industrialized countries is better educated than in former times and is thus aware of the complexity, interdependencies, and increase in the potential magnitude of consequences, it demands more scientific reasoning in the policy-making process and shows a high degree of awareness about arguments that are put forward to policy makers by scientists. At the same time the public is not willing to accept all the decisions that are formed by the legitimate policymaking bodies. The people claim that their interests have to be considered in the process of decision making and hence they demand more means of public participation. The incorporation of public concerns and the implementation of par- 
ticipation requires scientific consulting in order to design procedures and arenas that guarantee high quality of the decision output, as well as social stability and public transparency.

Modern societies are in urgent need of all four contributions that science can offer in principle. But we have not yet developed viable ways of structuring the necessary cooperation between the two subsystems, science and politics. There have been excellent records in small scale applications of scientific consulting, when defined problems have to be solved within local communities. But on a national or even an international level, the past experiences are less promising. In particular, no models exist to make use of the potentials of scientific expertise, while simultaneously avoiding the traps of ideology, technocracy or post-rationalization.

One attempt to structure such a model is the study of social compatibility of energy supply systems which is carried out by the research group, "Technology and Society" of the Nuclear Research Centre, in Jülich (Federal Republic of Germany).

The research grant was given to the program group "Technology and Society" of the Nuclear Research Centre Jülich by the Federal Ministry of Research and Technology. The objective of the German administration has been to evaluate strategies and options for future energy policies which should be socially acceptable and, at the same time, technically feasible. The technical options were developed by a Parliamentary Enquete Commission consisting of experts and politicians. This group came up with four different energy paths, or strategies, of how to cope with the future energy situation. The task of the Jülich study group was defined as an approach to reveal the conditions and prerequisites which are essential in order to end up with a social consensus on an acceptable and viable energy scenario. A similar research grant was given to a group of university professors of Essen and Frankfurt.

The project group was formed in the summer of 1982 and the research started in September of the same year. More than 10 subcontractors were involved, among them Ralph Keeney and Detlof von Winterfeld from the University of Southern California. The final research report will be presented to the Federal Ministry, as well as to the German Parliament, in October 1984. In which ways the results of this study will shape future energy policies, can not yet be predicted. But the considerable amount of research funds for this study and the continuous interest of politicians and administrators for obtaining more information about the results can be seen as indicators for a confined readiness to implement the recommendations into actual policies.

\section{Energy Policies: A Scrious Challenge for Social Science Consulting}

The Jülich Social Compatibility Study is based on the general assumption that the contribution of Social Sciences to facilitate conflict resolution can only be effective as long as the role of the scientist is confined to the process of catalysis, a term borrowed from chemistry which means, in our context, aiding or speeding up the social process of finding compromises without interfering with one's own values or preferences. Based on this general hypothesis five more refined assumptions were formulated which directed the empirical conceptualization of our approach:

1. Science and politics pursue different interests when cooperating with each other. The ideal scientist has the ambition to help the politician to find the best solution to a given problem, hence he looks for an optimization rule to choose between options according to expected outcomes. The ideal politician, however, wants to 
maximize public support and to retain the general trust in the principal ability of the political elite to handle complex issues and to master social conflicts. Hence, from his perspective, the justification of a decision is more important than the quality of its outcomes. This divergence of interests is inherently based on the specific functions that both subsystems perform within the overall societal system, regardless of whether more personal goals, such as gaining reputation, prestige, power, or money, are involved. The first requirement of our approach was to provide not only facts and models to assist the process of choosing the right option, but also to address the problem of legitimizing and implementing the best choice. If this problem turned out to be too difficult, the process has to be iterated until a second best solution is created. With both aims in mind we could serve a dual purpose: improvement of political efficiency and progress in scientific rationality.

2. Following our general requirement that the scientist should not insert personal values and preferences into the consulting task, some kind of a distinction between facts and values has to be made. At least we assumed that scientists belonging to different stake-holder groups can reach agreement on basic properties of objects or policies, if those properties can be measured physically (amount of emissions, cost, technical performance, reliability and so forth). Furthermore, we were convinced that even the spectrum of possible conclusions referring to uncertain events of future effects can be restricted to a limited range provided that scientists with different value backgrounds are willing to cooperate and that the situation in which the judgments have to be formulated facilitates agreement. It should be noted that we are not dernanding value-free research or neutral scientists. Instead we pursue a procedure in which factual knowledge is based on the agreement among scientists with various value commitments.

3. With respect to the value side we consider value-based preferences of any citizen as equally important compared to any other preferential judgment expressed by politicians or professionals. According to the democratic goal "one man-one vote," the sum of revealed public preferences should have the highest legitimate power.

4. In order to measure preferences of citizens in a valid manner the assumption has to be made that first the amount of knowledge necessary to express national preferences (referring to the expected consequences and their probabilities) can be gathered and transferred to the public and, secondly, that a common set of evaluative criteria can be established. The knowledge has to come from the experts in this field (cf, assumption 2). The criteria can best be formulated by those who are regarded as stake-holders in the respective issue.

5. Any compromise aiming towards conflict resolutions can only be implemented if at least the moderate stake-holder groups find a common agreement and the general public gains the feeling that their concerns were handled in a fair and serious manner.

Based on these five assumptions our final approach to introduce a complex model of consulting into energy policies consists of three basic elements.

Step 1: Identification and selection of concerns and evaluative criteria:

For this purpose the technique of value-tree analysis was used to elicit the general concerns and values present in contemporary German society. We interviewed rep- 
resentatives of nine leading social interest groups and asked for their values and concerns with respect to energy policy. The objective of this exercise was to collect all relevant values and concerns and to construct a common catalogue of criteria that all German stake-holder groups were able to agree on. This catalogue was used as a general yardstick for the assessment of probable consequences of each energy option (Step 2) and as a reference list to elicit the general preferences of the public (Step 3).

Step 2: The identification and measurement of impacts and consequences related to different energy options:

The criteria derived from the value tree were operationalized and transferred into indicators. Those indicators were formulated in such a way that they could be applied to energy systems as well as energy scenarios. Experts with different value preferences were asked to judge various energy systems and energy scenarios according to each indicator. In a joint venture the experts who had strongly disagreed on one or the other indicator were urged to find either a compromise or to define a range of possible solutions. This task was facilitated by an informal situation of face-toface interaction. For the social and political impacts a Delphi method was used to reach final agreement. In addition, some highly distinguished scientists or wellknown institutions, such as the Prognos Consulting Corporation in Switzerland, brought in their expertise to validate our ratings. The indicators and the final measurements were listed in a report without constructing indices or assigning weight to any of the indicators.[1].

Step 3: Aggregation and weighting of the impact profiles by randomly selected citizens:

In a four-day seminar, randomly selected citizens received all the necessary information to understand and handle the impact profile. They were also confronted with scientific and political arguments (via hearings) in support for each of the possible energy options. In order to restrict the scope of options, three to five local energy supply scenarios and four national scenarios (constructed by the Enquete Commission of the German Federal Parliament) had to be evaluated. It was the task of the participants to assign weights to each subcriterion and criterion of the indicator list (knowing the range of all scientifically derived ratings for each option) and to evaluate the overall performance of each scenario. Lastly, they had to give recommendations with respect to the demanded priorities in future energy policy-making.

The following sections will only deal with the third element: the elicitation of public preferences. This part of our study is not only the most ambitious one, but it encompasses a very new method of preference measurement: the concept of planning cells. As a matter of fact, this concept was used in our study for the first time on a national level. The instrument of planning cells claims to serve two basic purposes: measurement of public preferences and direct citizens' participation.

\section{"The Planning Cell" as Policy-making Instrument in the Decision-making Process}

The procedures for participation of the public in complex planning tasks that have been introduced and practiced up to now remain unsatisfactory in many respects. Peter C. Dienel has developed a new instrument for citizens' participation, the so-called "planning cell" [3]. The research unit "Citizens' Participation and Planning Procedures" at the University of Wuppertal has up to now tested this procedure in the field of siting, town planning, and urban renewal. This model claims to: 
1. Open up new possibilities of participation for the private citizen and

2. Improve the efficiency of decision making in the planning process.

Dienel defines the planning cell as "a group of citizens who are selected by a random process and are given paid leave from their workday obligations for a limited period of time in order to work out solutions for given, soluble planning problems with the assistance of advisors on procedure" [2].

The group, random sclection, time limit and the advisors on procedure are to be regarded as the significant structural elements in the planning cell. A group of citizens actually means a small group of about 25 people who work on the predefined task in a group process. Since the citizens involved have been selected by a random procedure they are not individually concerned in the planning problems to be solved. In order to encourage them to participate, they are assigned the socially highly esteemed role of a "consultant" in the public planning process. The seriousness of the planning task to be solved is also made clear by the honorarium which the citizen receives for his function as a "consultant." The limited participation period prevents the citizen from being alienated from his real social role; he only changes his perspectives for a brief period. This limited period prevents the arising of personal interests specific to the proceedings which would hinder planning appropriate to the task from being carried out. The final structural element to be mentioned is the advisors on procedure. The essential task of the advisors on procedure consists of ensuring that the necessary specialized information is presented and processed, and making an effective group process possible.

Figure 1 serves to illustrate the course of a planning cell's work. The flowchart shows that evaluation procedures take place in all phases of implementation. Individual evaluations, evaluations by the working groups and plenary sessions are collected with the aid of standardized evaluation questionnaires. The completed evaluation questionnaires represent in a certain way the skeleton output relevant to the planning task. The evaluation and processing of these results according to statistical methods is the main concern of the final working phase. In the last step, the so-called "citizens' report" is compiled and published from the insights and recommendations obtained with respect to solving the problems.

An advantage of the planning cell is the random distribution of participants, for this selection procedure distributes the changes of participation evenly. The social selectivity is thus offset - whereas in other procedures there tends to be a preponderance of members of the middle and upper classes, citizens of all classes are involved in a planning cell procedure. It is even more significant that by means of random selection a panel results in which the factor of direct interest is largely ruled out. In contrast, other technocratic and popular planning procedures are very strongly influenced by pressure groups; they are thus susceptible to strategic maneuvers and are often unable to form a consensus. The planning cell specifically offers those not concerned and thus not directly interested a possibility of mediation between polarized interest groups. In this way the unproportionate influence of pressure groups is avoided and the production of solutions to the problem capable of finding a consensus is also encouraged.

An increase in the efficiency of complex planning processes is derived from the following points:

1. It is founded on a broad data base due to the inclusion of heterogeneous social positions. 


\section{Sequential Phases in the Planning Cell's Work}

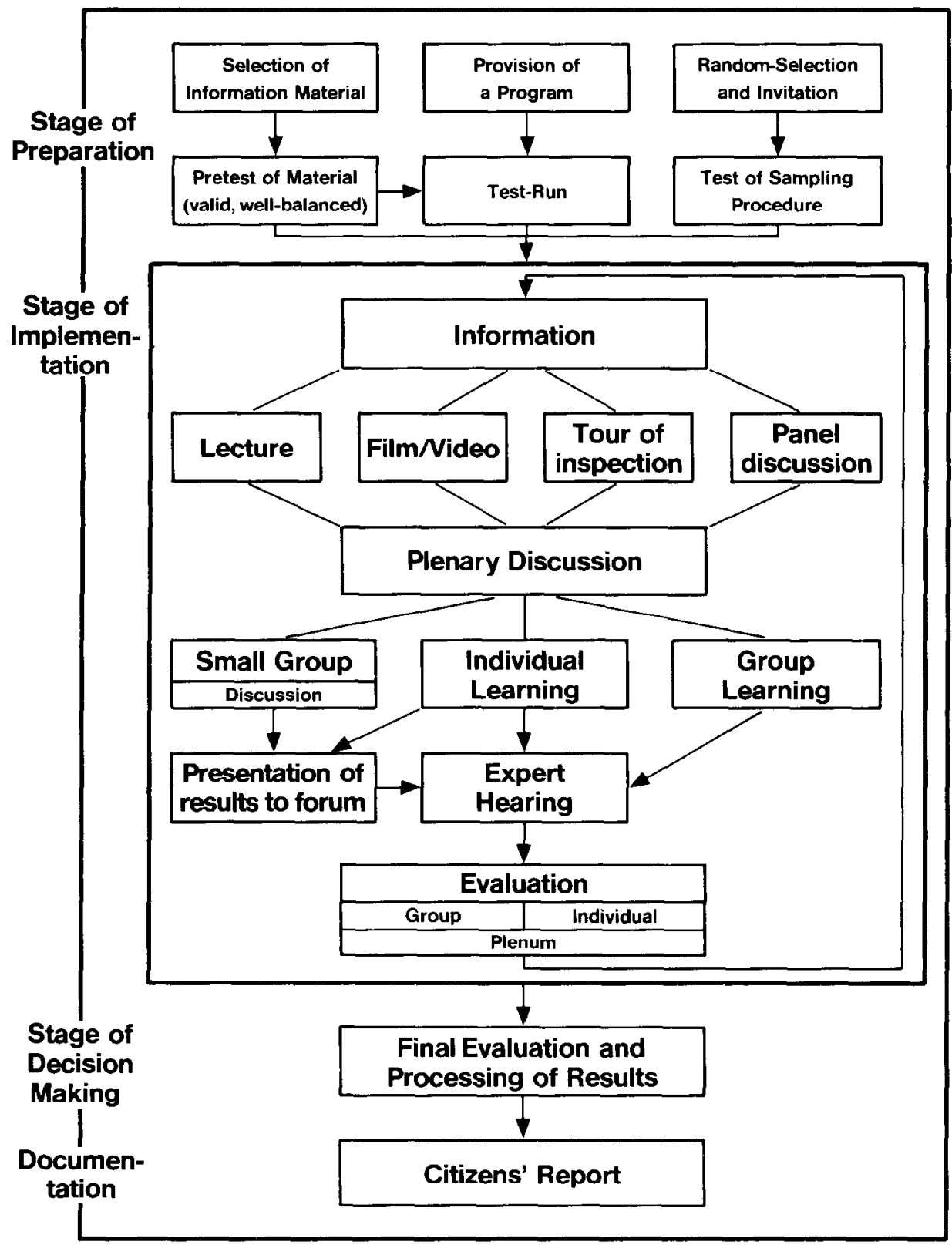

Fig. 1. Flowchart of the planning cell procedure.

2. The tendency of traditional policy-making bodies to fulfill no longer the planning tasks in a way appropriate to the tasks themselves but rather to the benefit of one's own institution, increased by bureaucratization and technocratic planning structures, is largely mitigated by the random selection and limited duration of the planning. 
3. New, unpredictible solutional approaches can be achieved on the basis of immediate practical experience and special needs of the citizens.

4. The inclusion of social values, which takes place by introducing the subjective values of the individual citizen, contributes to the ability to form a consensus on the solutions discovered.

In order to guarantee comparability of results, the information and evaluation procedures and the whole sequential situation must be standardized. This parallel connection neutralizes randomly occurring biases and distortions, and thus increases the representativeness of the planning output. This then provides the planning process with increased immunization against extcrnal pressurc. The implementation of several planning cell runs with similar results improves their validity and legitimation since even in the case of different constellations of interests, the same solutions might be worked out. Finally, this procedure is intended to render complex planning processes more controllable.

This last advantage seems to be doubtful at least. For the planning cell depends to a large extent on the amount of given information and the preliminary work by the sponsoring agency. Moreover, it can hardly control the process of decision making itself.

The complex of information is in general a problem for this procedure. The quality of the output relevant to planning is decisively dependent upon the quality of the factual information fed in. There is a great danger of manipulating the results via the selection and provision of information [9].

Another negative aspect should be mentioned. Probably the citizens will tend to prefer traditional solutions since, as representatives of the "silent majority," they will hardly be capable of suggesting innovatory approaches. 'The extensive integration of the procedure into the official planning processes is also criticized because this could lead to a rapid adaptation to existing schemes of decision making [9].

The random selection of the citizen is at the same time an exclusion procedure. This results in the disregard of an important principle of citizens' participation, namely that every interested party can participate in the planning. Even more important are the constitutional misgivings that imply a type of "ancillary parliament" could be constituted by the planning cells [6]. Even though it is clear that the citizens' report only makes recommendations and that parliamentary competence will not be encroached upon, it cannot eliminate the emerging problem of the double legitimization of political decisions.

Although the weakness of the procedure mentioned above should not be ignored, the "planning cell" model still offers specific advantages that justify its application in our project. In our opinion the advantages are the fact that those involved are not committed to any interest group, the acquisition of public preferences, and the representation of social values.

This procedure can assist in gathering insights that can contribute to improve the legitimization and also the efficiency of planning processes.

\section{The Basic Functions and Tasks of Planning Cells in the Jülich "Social Compatibility" Study}

In addition to the assumptions and requirements stated in the first chapter it is necessary for the application of the planning cell concept to consider the conditions and characteristics of the political arena in which energy policies have to be formulated and implemented. In contrast to some other political arenas, the energy scene is characterized by the following three major features: 
1. The lack of unanimity among the scientific experts about facts;

2. The lack of credibility with respect to scientists and policy makers on the side of the public; and

3. The lack of readiness of the stake-holders to engage themselves in the process of forming a compromise.

Any participation model aiming towards improving the decision-making process has to take these problems into account. A functional solution is only to be achieved if the following three requirements are met.

1. The scientific dissent must be represented within the participation process without frustrating people.

2. The legitimative power of the political decision-making process must be strengthened by introducing participation.

3. There is a need for a mediating force between the polarized stake-holder groups and this need has to be fulfilled by the participatory agents.

The planning cell model seems to serve these requirements. By compiling the necessary information profiles of performances for each energy option-constructed by scientists with different points of view - a legitimate way of conveying the basic facts to the participants was found without oppressing dissent, but also without creating frustration caused by confusion. In addition, experts with different opinions were invited to present their arguments. Small working groups within the planning cells were formed to process all the given information and to extract the factual input, on which all experts agree, from the subjective interpretation, where plausibility and social assumptions come into play. The purpose of improving the legitimacy of the political decision-making process and the depolarization of the conflict was pursued by random selection procedure. Since everybody was eligible to serve as a participant in the planning cell, the uninvolved citizen's opportunity for identifying with members of the planning cell was guarantecd to a greater extent than in the case of traditional decision makers. Without interest groups being represented the effect of polarization could be reduced, because a large number of participants with "in between" points of view were able to act as mediating agents.

Most specifically we expected three different types of outcomes as a result of the planning cell procedure.

\section{TASK-ORIENTED OUTCOME}

In order to avoid the mistake of overtaxing the ordinary citizen by filling his schedule with a number of sophisticated tasks, we reduced the amount of evaluative tasks to the following essential items.

1. Evaluating various energy systems and conservation technologies via multiple choice questions (simple attitude measurcment);

2. Evaluating one's own energy situation and describing future plans with reference to energy installations and insulation;

3. Weighting of the criteria and subcriteria to evaluate energy systems and scenarios;

4. Using the criteria-set to rate the overall performance of large-scale power plants and to rate the proposed consequences of four energy scenarios developed by the Enquete-Commission of the German Parliament; 
5. Making a final decision on the four energy scenarios and comparing this decision with the calculated result of the former ratings (using the algorithm $\Sigma$ criteria weight times score of rating);

6. Evaluating the local energy supply situation and suggesting new solutions to meet local energy problems;

7. Trying to establish a compromise between centralized and decentralized energy systems (group task).

\section{KNOWLEDGE-ORIENTED OUTCOME}

The classical date collection via survey techniques provides more or less random opinion profiles. In the case of the planning cell, however, the gathering of opinions is preceded by an information process. Thus it is possible to measure opinions or beliefs after they have gone through the cognitive stress of information and controversial discussions. In particular it is interesting to investigate the changes in opinion after information and discussions have taken place and to study the attitude-forming process as a function of social positions, general values, and demographic variables.

\section{POLICY-ORIENTED OUTCOME}

As a combination of the results of the evaluative tasks and the revealed social structure of preferences, general inferences can be made with regard to:

1. Suggestion of means to overcome polarization and to form compromises;

2. Identification of elements in energy policies that will likely meet serious public opposition;

3. The range of possible elements for constructing acceptable compromises.

\section{The Agenda of the Planning Cells}

The program of the planning cell's seminar was arranged in such a way that periods of relaying information, discussions, small group working periods, and evaluations via questionnaires were alternated.

The first day of the program started with a general introduction into the purpose and the procedure of the seminar. This introduction was followed by an inspection tour of a local energy facility. After visiting a power generation station or a central heating system, some of the key problems of energy supply and demand were disclosed and discussed. The local context was further described by the first lecture focusing on the possibilities and options to improve the local energy situation. After lunch this discussion was broadened to include the national perspective. Based on a short introduction of energy policies in Germany the participants - divided into small working groups - had to deal with some of the major problems of todays energy debate, such as waste heat utilization, oil supply, energy consumption or new energy sources. The purpose of these small group-arrangements was to impart familiarity with the present energy situation in Germany. At the end of the day the criteria to evaluate energy systems were introduced and explained. Again, working groups were formed (by random assignment) to simulate some practical applications of the criteria and subcriteria. The list of criteria and subcriteria are summarized in Table 1. The first day was completed by handing out a questionnaire asking for a rank ordering of the criteria by each participant individually. The four-day schedule of each planning cell procedure is summarized in Figure 2.

The second day was characterized by lectures containing the necessary information about energy technologies and their impacts. The lectures dealt with the following subjects: 
TABLE 1

List of Criteria and Subcriteria to Evaluate Energy Systems or Scenarios

1.0 Financial and Material Requirements

1.1 Cost of Today (Consumer, Investor)

1.2 Cost Development

1.3 Technical Material and Efficiency

2.0 Security of Supply

2.1 Availibility

2.2 Susceptibility to Technical Failutes

2.3 Reserves and Resources of Energy

2.4 Potential to Meet Energy Demand

2.5 Flexibility

3.0 Economic Effects

3.1 Labour Market

3.2 National Competitiveness

3.3 Structural Development

4.0 Environmental Impacts

4.1 Local Consequences

4.2 National Consequences

4.3 Global Effects

5.0 Health and Safety

5.1 Risks for the Employees
5.2 Risks for the Public

5.3 Potential Threat of Catastrophes

5.4 Problems for Future Generations

6.0 Social Impacts

6.1 Standard of Living

6.2 Social Justice

6.3 Social Security

6.4 Impacts for the Working Place

6.5 Flexibility for Life-Styles

6.6 Personal Well-being

7.0 Political Impacts

7.1 Impacts on Constitutional Rights

7.2 Impacts on Decision-Making Process

7.3 Level of Self-Determination

7.4 Impacts on Political Stability

8.0 International Effects

8.1 Impacts on International Trade

8.2 Peace

8.3 International Justice (Distribution of Wealth)

fossil fuel, heating systems, energy conservation, renewable energy sources, power generation, and nuclear energy. For each of these subjects an expert from universities or from other uncommitted research institutes was invited to present the basic information. After each lesson the participants, gathered in small groups, discusscd the important topics and directed specific questions to the lecturer. At the end of each session a ques-

Social Compatibility of Energy Systems: Agenda of the Planning Cells

\begin{tabular}{|c|c|c|c|c|}
\hline & Tuesday & Wednesday & Thursday & Friday \\
\hline Session 1 & $\begin{array}{l}\text { Introduction: } \\
\text { The Energy Situation }\end{array}$ & $\begin{array}{l}\text { Fossil Energy } \\
\text { Heating Systems }\end{array}$ & $\begin{array}{l}\text { City Planning and } \\
\text { Energy Supply } \\
\text { or } \\
\text { Continuation of Session } \\
4 \text { of Wednesday }\end{array}$ & $\begin{array}{l}\text { Generation of Goals } \\
\text { and Aims for Cnergy } \\
\text { Policies }\end{array}$ \\
\hline Session 2 & $\begin{array}{l}\text { Inspection Tour of } \\
\text { Local Energy Facility }\end{array}$ & $\begin{array}{l}\text { Energy Conservation } \\
\text { Renewable Energy } \\
\text { Sources }\end{array}$ & $\begin{array}{l}\text { Introduction to } 4 \text { Energy } \\
\text { Options } \\
\text { Group Evaluation of } \\
\text { Options }\end{array}$ & $\begin{array}{l}\text { Final Evaluation: } \\
\text { Local Energy Situation } \\
\text { (Recommendations) }\end{array}$ \\
\hline & Lunch & Lunch & Lunch & Lunch \\
\hline Session 3 & $\begin{array}{l}\text { Local Energy Supply } \\
\text { and Demand: } \\
\text { Situation and Options }\end{array}$ & Nuclear Energy & & $\begin{array}{l}\text { Individual Evaluation } \\
\text { and Decision on the four } \\
\text { Energy Options }\end{array}$ \\
\hline Session 4 & $\begin{array}{l}\text { Introduction of } \\
\text { Evaluation Criteria }\end{array}$ & $\begin{array}{l}\text { Electrical Power } \\
\text { Generation } \\
\text { Evaluation of Power } \\
\text { Generation Plants }\end{array}$ & Political Hearing & $\begin{array}{l}\text { Continuation of } \\
\text { Session } 3 \\
\text { Evaluation of the } \\
\text { Scminar and the } \\
\text { Participatory Process }\end{array}$ \\
\hline
\end{tabular}

*The four energy options have been developed by the German Parliamentary Enquete-Commission on nuclear energy

Fig. 2. Agenda of the planning cells. 
tionnaire asking for the general feeling of favorableness or uneasiness with respect to the discussed topic was distributed to all participants.

In the preliminary test runs of the planning cells the controversial issues of nuclear and solar energy were presented by two speakers holding opposite points of view. This procedure proved to be very time-consuming and frustrating because of the confusion caused by the controversial live debate. Instead we prepared two video tapes containing precise statements of the nation's leading pronuclear and antinuclear, as well as prosolar and antisolar advocates. These statements were ordered according to the criteria lists we had already introduced to the participants on the first day of the seminar. In addition, we invited two technical experts - one with a moderate pronuclear, one with a moderate prosolar point of view - to present the technical information and to answer questions. With the exception of the planning cell run at Berlin, where the energy seminar had been conducted for the first time, this procedure was regarded as neutral and well-balanced by all participants.

At the end of the second day we arranged a first trial for the participants to work with the given set of criteria. The task was to evaluate different power plant systems according to the eight criteria and the 31 subcriteria. Small groups of 3 to 5 participants were asked to assign ratings ranging from -2 to +2 to each subcriterion. The rating referred to the evaluation of nuclear, coal, hydro, oil, solar and wind power. Then an index had to be constructed summarizing the overall intentions of all subcriteria and reflecting the final evaluation of a given power plant with respect to each main criterion. This complex task was not entirely performed by each small working group. Only two criteria and the corresponding subcriteria were assigned to each group for evaluation. After the rating procedure the speakers of the small groups had to report on their ratings and to explain their reasons for arriving at a particular rating. No instructions were given for reaching an agreement within one working group. With the exception of two cases, unanimity was achieved without interference by the chairman. In order to facilitate the rating procedure and to make the evaluation more accurate, the results of our impact analysis were handed out to all participants and explained to them. Since the impact analysis contained only the scores of the selected indicators, leaving open the spaces for the evaluation of the subcriteria and criteria, factual information was given, without prejudicing the subjective ratings of each group. As already mentioned, the impact analysis contained only those indicator scores that were uncontested. If there was dissent, this was indicated by reporting both estimations.

The evaluation of the five options to generate electricity consumed more time than we initially anticipated. On an average each group took approximately 1 to 2 hours to make the evaluation of one criterion (summarizing up to four subcriteria). Although we occasionally observed strategic response patterns assigning only positive evaluations to the most favoured candidate negative ones to the least favoured, most participants were highly motivated to fulfill their task as accurately and reasonably as possible. Since our main goal was to end up with a well-balanced judgment by the participants, we tried not to push the citizens to hasten in determining their ratings, but extended this session to the morning of the next day, skipping the planned session on city planning and energy demand.

Accordingly, the third day started with the completion of the questionnaire for the power plant evaluation. In the second session, two members of the scientific secretariat of the German Enquete Commission of the German Parliament on Nuclear Energy presented the four energy scenarios dealing with possible energy futures in the Federal Republic of Germany. The scenarios were constructed in such a way that different political 
options were operationalized in terms of consistent energy supply and demand models for the years 2000 and 2030 . One of the two speakers explained the four scenarios to the audience and pointed out the main differences between them (the four scenarios are illustrated in Figure 3).

In particular, the role of nuclear energy (option 1 and 2 utilizing this technology to a large extent, options 3 and 4 rejecting it) and the role of energy conservation and solar systems (options 1 and 2 with a moderate amount of conservational and solar technologies, options 3 and 4 concentrating on these two) were discussed in detail. A working-group session was organized after the lecture to make the participants more familiar with the fundamental structure of the scenarios. They could also raise questions and direct them to the two speakers of the scientific secretariat. Needless to say, one speaker preferred options 1 or 2 , while the other favored options 3 or 4 . Before lunch the participants went through the same exercise as the day before: they were asked to evaluate the four scenarios according to the subcriteria and to form indices for each criterion. As an additional task,

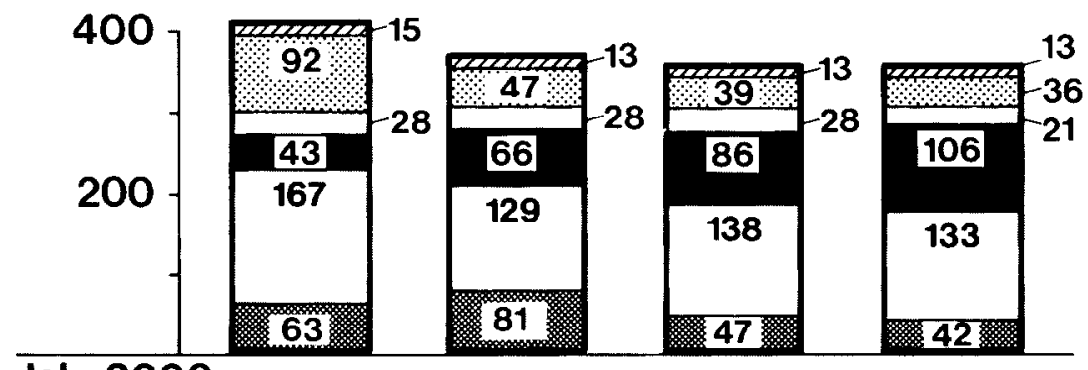

\section{Jahr 2000}

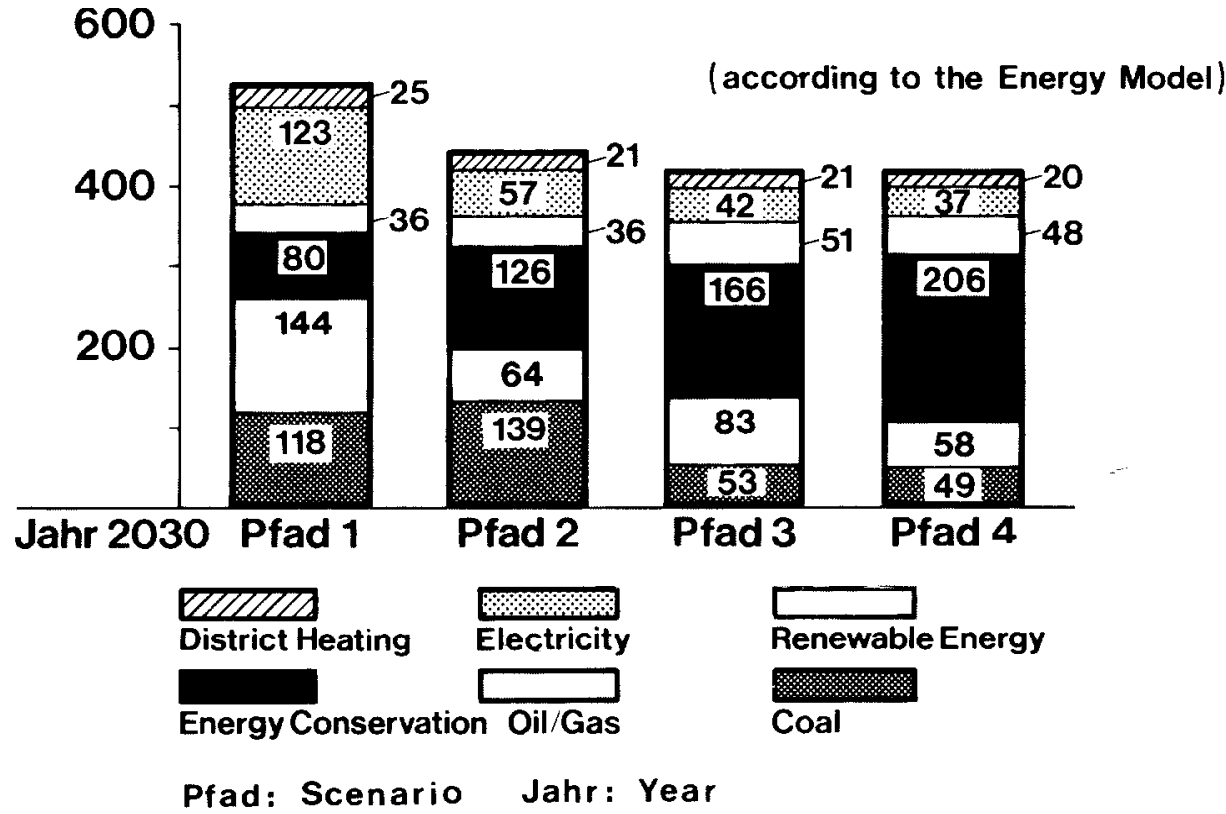

Fig. 3. The end-energy demand according to the four energy scenarios of the German Parliamentary Enquete Commission. 
they had to perform a provisional weighting of the subcritcria in order to make the construction of the indices more valid. Again this task was done in small groups.

In the afternoon a hearing was organized between the audience and politicians from the German Parliament representing the four parties (Christian Democrats, Social Democrats, Liberal Party and Green Party). The objective of this hearing was to make the participants familiar with the political arguments relatcd to cach of the four options. The hearing also served to strengthen the confidence of the participants in their judgment. After two and a half days of intensive learning most citizens had gained a degree of expertise which sometimes was superior to the knowledge of the politicians represented at the podium. The reactions of the politicians upon realizing that ordinary citizens were able to detect technical mistakes or biased argumentation varicd from astonishment to anger.

Supported by this experience, the participants were asked to give their final judgment on the fourth day. In a first session they went through an exercise of generating their own evaluative criteria by defining social goals and aims that should be met by energy systems. Afterwards the local energy situation was discussed again. Some recommendations were formulated to improve the work of the regional planning agency.

Both afternoon sessions were reserved for the individual evaluation of the four energy options of the German Enquete Commission. The evaluation process was divided into seven steps:

1. Rank ordering of the criteria;

2. Assigning of cardinal weights to each criterion;

3. Rating each of the four scenarios according to each of the eight criteria (scores ranging from -2 to +2 ) on the basis of our impact profiles;

4. Intuitively judging of the best and second best scenario;

5. Contrasting of the intuitive judgment with the calculated result of the rating and weighting process (using the formula $\Sigma$ criteria weights multiplied by scenario ratings);

6. Subjectively explaining the resulting discrepancies between the intuitive and the calculated results;

7. Collecting of political arguments to "sell" one's own decision to the general public.

Whereas steps 1-4 and 7 are self-explanatory, steps 5 and 6 need a little more elaboration. After the participants had indicated their intuitive preferences with respect to the four options, they could relax during a coffee break. During this time the individually assigned weights for each criterion and the ratings for the evaluation of the four options were multiplied and summed up for each of the four scenarios. The procedure, the arithmetics and the results were then presented to the participants. If a discrepancy between the intuitive and the calculated preference order occurred, the respondent was handed out a questionnaire to write down the possible reasons for this gap. Specifically, if the list of criteria was regarded as incomplete, we asked if there were interactional effects between the criteria (nonlinear relationships) or if the respondents had objections concerning our model. These questions came close to the borderline of the mental ability of many participants, causing some frustration and demotivation. But by explaining the task to 
each individual separately and giving him the feeling of doing extremely well, we were able to reaffirm his attention and to reveal some of the underlying causes that probably initiated the gap between the intuitive and the calculated results.

Finally, the participants were asked to evaluate the whole seminar as well as their own role of being lay consultants. Before departing they were also requested to fill out a questionnaire regarding their personal data (age, sex, income, education, profession, party affiliation, opinion leader scale, religion, family status, and others). A glass of champagne and a check for the honorarium of being a consultant marked the end of the seminar.

\section{The Implementation of the Planning Cells}

In the time period from June 1982 through April of 1983 we organized 24 planning cells at seven German locations. Four test runs had been carried out in two German towns to develop valid and reliable scaling techniques and to test our program agenda. Substantial changes were made after the pretests. Therefore fully comparable data is only available for 20 planning cells. Since the number of citizens who participated at each planning cell seminar varied from 12 to 32 , we did not end up with 500 persons, but only with 427 . Adding to this number the participants of the pretest, 482 citizens took part in our study.

The selection of the locations to run planning cells was made according to the following specifications:

1. Representation of all major regions in Germany;

2. Variation in size of population;

3. Variation of building structures and housing devclopment;

4. Variation of environmental quality; and

5. Representation of familiar and unfamiliar energy supply situations (including renewable energy sources).

As a further selection rule we considered only those locations where investigations of the local energy structure had been carried out before, so that we could use existing reports or written material would provide the necessary information to prepare the local options and to describe possibilities to improve the regional energy situation.

By following these rules to choose the appropriate towns and cities, we found seven locations which seemed to fit into our list of requirements:

1. Berlin-Neukölln: Part of the city of Berlin, 300,000 inhabitants of predominantly low social status, mainly old buildings, reconstruction measures underway (sanitation), large amount of old-fashioned heating systems, high pollution.

2. Gelsenkirchen: Larger city in the Ruhr-district, approximately 300,000 inhabitants, 100,000 living in the center, predominantly members of the working class, densely populated and highly industrialized area, high proportion of foreign workers, mainly old, some renovated buildings, high amount of coal-fired systems, extremely high pollution.

3. Offenbach: Small city of about 100,000 inhabitants of predominantly medium social status, in the center of the southwest, densely populated industrial areas, mixture of old and new buildings, high potential for district heating because of industrial waste heat, high pollution.

4. Norderstedt: Typical affluent suburban area on the outskirts of Hamburg, about 66,000 inhabitants of medium and high status, predominantly recently built, 
single-family homes with backyards, some applications of solar energy, medium pollution.

5. Viersen: Medium-sized town of about 80,000 inhabitants of predominantly high medium status, mixture of rural and industrial structure, more new than old buildings, high amount of electrical heating systems, low to medium pollution.

6. Soest: Medium-sized town in the neighborhood of a densely populated industrialized area (Ruhr-district), 40,000 inhabitants of predominantly medium status, mixture of old and new buildings, mainly gas and oil heating, resort area for the industrial centers nearby, medium pollution.

7. Neustadt an der Waldnaab: Small rural town of 5,600 inhabitants of predominantly low and medium status, small center with old buildings, new single-family homes in the development areas, mainly oil or wood heating systems, good potential for renewable energy (in particular, biogas), low pollution.

After the seven towns had been chosen, the random selection of participants for our seminar took place. For this purpose we used the central register at the town hall in which the addresses of all inhabitants are listed. (In Germany any resident has to register at his/her home town.) According to previous experiences with planning cells, we needed about 100 addresses to secure 25 participants. Thus we counted on a $75 \%$ failure or refusal rate. This assumption proved too optimistic. An average of only $20 \%$ of all persons we invited to participate actually attended our seminar. The invitation process itself underwent three stages:

1. Formal invitation letter containing the purpose of the seminar, the general idea of the planning cell method and some details of the contract that had to be signed by the participants (for example, concerning the honorarium).

2. Personal visit to each potential participant by one member of the research team to explain personally the details of the planning cell and to prepare the contract.

3 . If necessary, personal or telephone requests to the employer of each potential participant asking for the permission to grant his employee a four-day vacation.

The organization of planning cells is a highly complex task. Baby-sitting services have to be provided, adequate rooming has to be found, the local authorities must be consulted and the local press informed. All this necessary preparation was carried out by the University of Wuppertal under the direction of Prof. P. Dienel and his colleagues. The contract was signed only by Prof. Dienel or his substitute to avoid any commitment or compliance effects that might occur if the name "Nuclear Research Centre" appeared on the contract. (Working out the program, setting up the agenda, preparing the evaluations and running the scenarios were all a joint venture of the Nuclear Research Centre and the University of Wuppertal).

The high number of refusals to participate (about $80 \%$ ) was primarily due to job or family ties that prevented many potential participants from accepting the invitation. Some persons were not satisfied with the honorarium that we offered, some expressed their lack of interest in the subject, some were opposed to the procedure in general or just irritated, some had other commitments, and so on. It was surprising, though, that only few respondents refused because of self-perceived incompetence. Although some women insisted that their husbands or sons would have been a much better choice, most times they could be persuaded to attend the seminar. It was sufficient to explain the random selection technique and its relevance for the representativeness of the results. Of course, 
TABLE 2

Sex Distribution

(Comparison of Planning Cells with German Population)

\begin{tabular}{ccc}
\hline & $\begin{array}{c}\text { Planning } \\
\text { Cells } \\
(n=482)\end{array}$ & $\begin{array}{c}\text { Total } \\
\text { Population } \\
(n \approx 47 \mathrm{Mio} .)\end{array}$ \\
\hline Sex & $53.1 \%$ & $47.7 \%$ \\
Male & $46.9 \%$ & $52.3 \%$ \\
\hline
\end{tabular}

${ }^{a}$ West-German Population $\geqslant 18$ years.

Source: Statistical Yearbook of the Federal Republic of Germany 1981, edited by Statistiches Bundesamt Wiesbaden 1981.

it is possible that the feeling of incompetence was a latent cause of refusal, but for social status reasons it was not explicitly expressed to the research team.

Of the invitations that were accepted, only four persons out of 487 did not show up on the first day of the seminar, and only one person dropped out of the seminar before it ended. In spite of this encouraging experience, a success rate of 20 out of 100 makes it difficult to draw statistical inferences and to predict the general public attitudes or beliefs. Since family or professional commitments are not distributed equally, we expected some systematic distortions. Surprisingly the dispersion of demographic characteristics came very close to the general distribution reported for the population of Germany. As can be seen in Tables 2 and 3 , there were only minor differences in the distribution of sex and age classes (considering the fact that we restricted our samples to persons above 18 years of age).

There was also a fairly good representation of all social classes in our samples with a slight over-representation of middle classes and a slight under-representation of high classes. The strongest bias that we were able to detect referred to professional affiliations. Compared with the national average, we had attracted far too many white collar workers (in particular, government employees) and not enough members of the working class. (This is indicated in Table 4.) We also were confronted with an over-representation of students, both from high school and college. Since students have more time to spare, this bias is not astonishing. The percentage of housewives, unemployed, or retircd persons did not deviate from the general average in spite of the expectation that these groups are likely to be over-represented if paid for attendance.

TABLE 3

Distribution of Age Classes

(Comparison of Planning Cells with German Population)

\begin{tabular}{ccc}
\hline Age & Planning Cell & Total Population $^{a}$ \\
\hline $18-25$ & $16.6 \%$ & $13.9 \%$ \\
$26-35$ & $22.2 \%$ & $17.3 \%$ \\
$36-45$ & $21.0 \%$ & $20.0 \%$ \\
$46-55$ & $17.2 \%$ & $16.0 \%$ \\
$56-65$ & $16.0 \%$ & $12.5 \%$ \\
$>65$ & $6.0 \%$ & $20.3 \%$ \\
Missing & $1.0 \%$ & \\
& $100.0 \%$ & $100.0 \%$ \\
\hline
\end{tabular}

${ }^{a}$ West-German Population $\geqslant 18$ years

Source: Statistical Yearbook of the Federal Republic of Germany 1981, edited by Statistisches Bundesamt Wiesbaden 1981 
TABLE 4

Distribution of Professional Affiliations

\begin{tabular}{lr}
\hline Self-Employed & $3.73 \%$ \\
Employees & $31.33 \%$ \\
Government and Public Employees & $9.34 \%$ \\
Workers & $10.79 \%$ \\
Housewives & $19.09 \%$ \\
Students & $9.75 \%$ \\
Retired Persons & $13.90 \%$ \\
Missing & $2.10 \%$ \\
$n=482$ & $100.00 \%$ \\
\hline
\end{tabular}

Looking over these results we may conclude that the samples can neither be regarded as representative for the whole German population, nor for the locations that we had selected. But the dispersion of demographic characteristics and professions within the samples justifies the use of inferential statistics with respect to relations between defined social groups. By comparing the results of the planning cells with similar results of national surveys we might also be able to validate some general conclusions. These can be found by combining specific results of the planning cells with similar tendencies revealed in representative surveys.

\section{The Results of the Planning Cells}

The last run of a planning cell seminar took place in April 1983. In the following months the phase of data processing was started, but has not been completed up to now. Thus we are only able to report on a selection of results which have been analyzed so far. Specifically we concentrated our efforts on studying the preference structure of the citizens with respect to the four energy scenarios; however, we also looked into the general attitude and belief structure. For this article we selected the following topics:

1. Beliefs about different energy systems;

2. Weights and rank order of criteria;

3. Preference structure with respect to the four energy options of the Enquete Commission; and

4. Predictive power of the utility and factor models reflecting the intuitive decision.

After the presentation of the results we will draw some general conclusions about the lessons we learned about the merits and pitfalls of the planning cell instrument.

\section{BELIEFS ABOUT DIFFERENT ENERGY SYSTEMS}

In all planning cells we found rather clearcut beliefs concerning the different energy systems. Coal energy was perceived as a native energy source and thus was seen as both beneficial to society, but also as environmentally harmful. An overwhelming majority favored strict antipollution laws for coal-fired power stations, even if consumers had to pay higher prices for their electricity. Many participants refused to make tradeoffs between environmental quality and cost when deciding on the impacts of coal energy. In order to prevent acid rain problems and the deterioration of the German forest-the "hottest" political issue in Germany in 1983 with respect to the environment--they demanded immediate action to be taken, regardless the cost.

With respect to oil and gas, most people feared dependency on supplier nations, but this topic did not have the same saliency or emotional power compared to the issue of 
environmental quality. The reliance on more native energy sources was unanimously requested, but not for the price of major economic disadvantages or consumers' reduction of utilities. Since coal was regarded as environmentally harmful and oil and gas as politically dangerous, the future hope focused on solar energy and conservation. There were high expectations concerning the potentials of the alternative technologies or solar systems, but a very low personal interest in purchasing one. Most people believed that solar energy was not yet technically feasible and that the systems would be improved over time. Most participants agreed with the statement that the Federal Government of Germany should spend more money for research and development of solar systems. These programs should be financed by reducing the research grants for nuclear energy, by raising the price of electricity (but only modestly) or by transferring money from other parts of the federal budget. As expected, tax increase was the least popular method for financing solar research.

Tcchnologics for energy conservation (insulation, the heat pump, passive solar utilization) were also highly approved by most of the participants. There were few objections to state intervention into the market economy in order to speed up the market penetration of conservation technologies. Stricter laws or regulations concerning insulation or building permits were demanded from government, even in view of the fact that such regulation would raise the cost of building new homes. However, there were clear indications that governmental regulations restricting consumption or controlling individual heating behavior were unanimously rejected.

In spite of the general favorableness of conservation, each individual perceived only a limited scope of possibilities to save more energy in his/her home. A vast majority (over $70 \%$ ) of all participants indicated that they either perceived no chance of implementing new conservational installations or that they were convinced that they had already done everything possible. Institutional, economic, structural, and social barriers restraining an effective conservational program, were frequently mentioned, but only few generic ideas were expressed on how to overcome these difficulties. There was high support for the suggestion that the government should finance conservational installations in advance and should then be repaid by the customer out of the surplus money he had saved by consuming less energy.

We experienced a very ambivalent reaction towards nuclear energy. Approximately $30 \%$ of all participants were fundamentally opposed to any use of nuclear power. This group perceived nuclear energy as being expensive, environmentally harmful, dangerous, and socially unacceptable. Information containing positive arguments was rejected either as interest-driven manipulation or as short-term thinking. This specific group also criticized the ratings of our impact analysis as soon as they discovered any positive scoring for nuclear energy. The distrust concerning the nuclear ratings was not extended to the scores of the other energy systems.

The vast majority of all participants showed a strong degree of ambiguity: on the one hand they perceived nuclear power as necessary, economical, and promising, but on the other hand they expressed a strong degree of discomfort with this type of electricity generation. Most people supported the recommendation to confine the use of nuclear energy to that amount that all other energy sources together could not meet. The difficulties encountered in this limitation of nuclear growth were well understood (in particular, the question of who determines the amount of nuclear energy that cannot be substituted for). In spite of this problem most participants expressed their feeling that the nuclear program should be restricted to the minimum of what should be regarded as necessary and that 
nuclear installations should be replaced, if other technically or economically feasible solutions were available. However, almost everyone of this majority group voted against a complete shutdown of nuclear power plants. They were convinced that nuclear energy might play a major role in the future, provided the safety problems, the reprocessing and waste disposal problems, and the negative social impact (like police state methods) could be managed in a satisfactory way. Also most people believed that in the long run nuclear energy had the potential to be the most important energy source for the Federal Republic of Germany, but the appropriate technology for this purpose was still to be developed.

\section{WEIGHTS AND RANK ORDER OF CRITERIA}

For the purpose of evaluating the four options of the Enquete Commission of the German Parliament, eight criteria and 31 subcriteria had been handed out to the participants. The task of the participants was to assign weights to each subcriterion and criterion, and later on to evaluate the four options according to each criterion. The theoretical approach was based on a modified MAU-model by simplifying the utility measurement. Since we deliberately provided extensive information about the four options and the criteria, we had to control the effects of our information input on the participants' scoring behavior. We assumed that the rank order of criteria was derived from personal values and should therefore not be altered by the information process; our information was meant to focus only on facts and their (controversial) interpretation. In order to test the influence of the information process, we asked the participants to make a rank order of the main criteria on the first and the last day of the seminar.

Figure 4 illustrates the medians of the rank order for all eight criteria, comparing first and second measurement. Evidently all observed changes are only of minor magnitude and the sequential order remains the same.

Based on the individual scores, however, there is a high degree of change between the first and the second measurement. But these differences vary in general between one or two places up or down the rank order. The reason for these alterations is probably based on random effects (lack of memory) and not on real shifts in value preferences. The contingency coefficient ${ }^{1}$ exceeded the amount of 0.60 for all criteria. We were also able to prove that the preference structure of our samples was rather similar to the preference structure that had been measured in previous commercial survey studies (for instance, Infratest Poll, 1981). So we are justified to conclude that our samples represent the view of the general population fairly well, and that our information process has obviously not changed the preference order.

Looking at the priorities revealed by the weighting procedure it does not seem surprising (knowing the general beliefs) that health/safety and environmental quality from the top of the hierarchy. The general economic concerns-in particular, security of supply-are rated higher than the more specific concerns of financial and material requirements. It is interesting to note, though, that this criterion gained more importance over the four days information period, whereas the relevance of the environmental effects is rated slightly lower on the last day compared with the rating of the first day. Political, social and international aspects were regarded as less important for the evaluation of energy systems.

${ }^{1}$ Pearson contingency coefficient:

$$
c=\sqrt{\frac{x^{2}}{N+x^{2}}}
$$




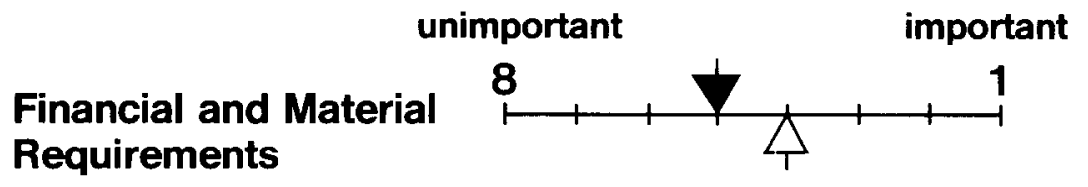

Security of Supply

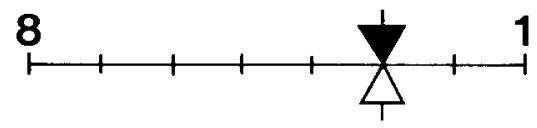

Economic Effects

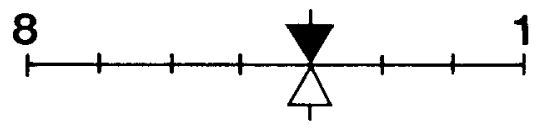

Environmental Impacts

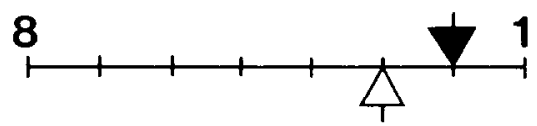

Health and Safety

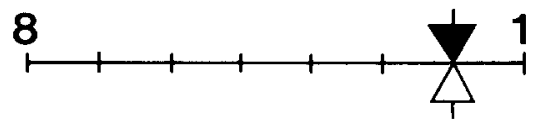

\section{Social Impacts}

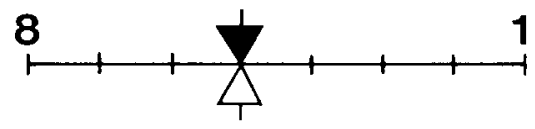

\section{Political Impacts}

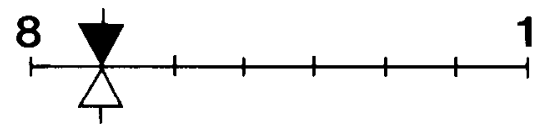

\section{International Effects}

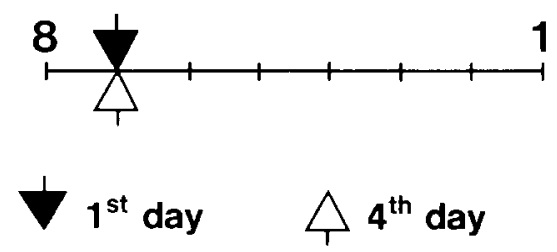

Fig. 4. Comparison of rank order of criteria at the beginning and at the end of the planning cell run (medians).

We performed a subdivision of the cardinal weighting scores (ranging from 0 to 100) according to the intuitive preference for one of the four cncrgy scenarios in order to analyze how the importances of criteria vary when individuals prefer a more nuclear, or a more solar oriented energy option. In Table 5 the criteria weights are listed, subdivided according to the scenario preferences. Table 5 conveys the immediate impression that the weighting scores do not differ dramatically, even in the most prominent cases of scenario 1 and 4 . The means of the weights for economic impacts, health and safety, political impacts, and international effects are not significantly different between the respondents in favor of the pronuclear scenario 2 and the respondents in favor of the nonnuclear scenario 3 . It is probably no surprise that proponents of a nuclear scenario assign more weight to cost and less to environment and social impacts. More astonishing is the unexpected homogeneity between the different preferential groups. The saliency of social values cannot be the decisive factor in forming energy preferences. 
TABLE 5

Weights of the Eight Criteria as a Function of the Preference for One of the Four Energy Scenarios (Means)

\begin{tabular}{lcrrrr}
\hline & & & & & $t-$ Test \\
& 1 & 2 & 3 & 4 & 0.00 \\
\hline 1. Financial and Material Requirements & 16.25 & 12.65 & 9.49 & 8.48 & 0.00 \\
2. Security of Supply & 20.42 & 17.72 & 15.23 & 11.83 & 0.00 \\
3. Economic Effects & 18.33 & 13.26 & 13.04 & 10.0 & 0.71 \\
4. Environmental Impacts & 12.25 & 16.20 & 19.10 & 22.66 & 0.00 \\
5. Health and Safety & 13.08 & 18.89 & 20.14 & 20.60 & 0.08 \\
6. Social Impacts & 8.75 & 9.57 & 11.52 & 13.96 & 0.00 \\
7. Political Impacts & 7.67 & 6.51 & 7.36 & 8.0 & 0.05 \\
8. International Effects & 8.5 & 6.71 & 7.12 & 9.30 & 0.37 \\
\hline
\end{tabular}

The preferences for one of the four energy scenarios are much more determined by the perceived performance of the four energy scenarios with respect to the eight criteria. This is illustrated in Table 6, which lists some selected ratings of the four energy scenarios subdivided again according to the intuitive scenario preference. The range of possible evaluations is restricted from -2 to +2 .

In contrast to the weights given to each criterion, the ratings for the performance of each scenario differ considerably. All respondents belief that environmental quality and health/safety impacts should be regarded as the most important criteria to make judgments about different energy systems. But the judgment whether nuclear or solar scenarios should be evaluated as superior when those criteria are used as yardsticks, reveals the gap between the different preferential groups quite clearly. Thus, there is much more agreement on the weights to be assigned to various criteria as on the perceived properties of each evaluated option with respect to this criterion. This conclusion can be confirmed by a variety of other studies in Germany and the United States [8].

\section{THE INTUITIVE AND CALCULATED PREFERENCE STRUCTURE}

\section{WITH RESPECT TO THE FOUR ENERGY SCENARIOS}

Figure 5 shows the results of the intuitive preference measurement and of the calculated preferential order. Intuitively the moderate pronuclear option 2 has gained the highest approval, followed by the most moderate non-nuclear option 3. Most of the

TABLE 6

Unweighted Ratings of the Four Energy Scenarios as a Function of the Preference for One of the Four Scenarios (Means)

\begin{tabular}{|c|c|c|c|c|c|c|}
\hline Preference for: & & 1 & 2 & 3 & 4 & $\begin{array}{c}t \text {-Test } \\
p(2 \text { vs } 3)\end{array}$ \\
\hline \multirow[t]{2}{*}{ Economic Effects } & Scenario 2 & 0.58 & 0.82 & 0.26 & -0.37 & 0.00 \\
\hline & Scenario 3 & -0.42 & 0.15 & 0.55 & 0.51 & 0.00 \\
\hline \multirow[t]{2}{*}{ Environmental Impacts } & Scenario 2 & -0.50 & -0.16 & -0.65 & -0.95 & 0.00 \\
\hline & Scenario 3 & 0.85 & 0.40 & 0.69 & 0.26 & 0.00 \\
\hline \multirow[t]{2}{*}{ Political Impacts } & Scenario 2 & 0.33 & 0.3 & -0.31 & -0.93 & 0.00 \\
\hline & Scenario 3 & -0.58 & 0.25 & 0.68 & 0.70 & 0.00 \\
\hline \multirow[t]{2}{*}{ International Effects } & Scenario 2 & 0.08 & 0.16 & -0.28 & -0.95 & 0.00 \\
\hline & Scenario 3 & -0.08 & 0.27 & 0.59 & 0.74 & 0.00 \\
\hline
\end{tabular}




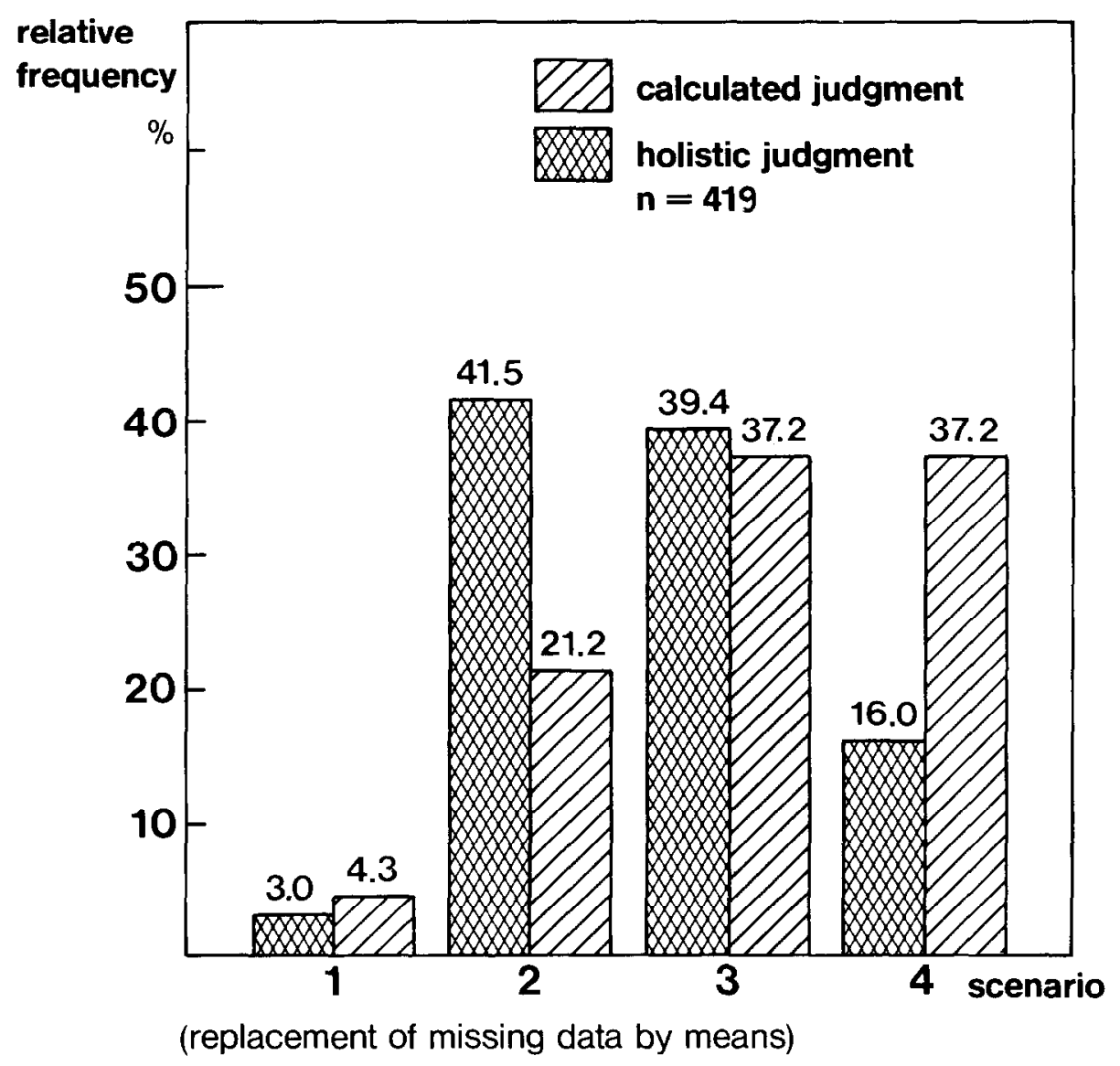

Fig. 5. Holistic and calculated judgment on the preference for one of the four scenarios.

respondents who gave first priority to option 2 or 3 assigned also the second priority to the other moderate option (either scenario 2 or 3 , respectively). Thus, there is a clear indication for the preference of more moderate scenarios.

The two pronuclear options together were chosen less frequently than the two nonnuclear options. Approximately $16 \%$ of participants preferred the extreme solar and conservational scenario 4 as opposed to only $3 \%$ preferring the extreme pronuclear scenario 1. Thus there is a considerable group of highly motivated and convinced citizens with a strong antinuclear commitment, whereas an equally sized pronuclear fraction is missing. Also, more than $70 \%$ of the persons who preferred option 2 (moderate pronuclear) inoved to the moderate non-nuclear scenario 3 when asked for the second priority. The proponents of scenario 3, however, were equally divided: $50 \%$ assigned their second priority to scenario 2 , the other $50 \%$ to scenario 4 . So in spite of the highest score for the moderate pronuclear option 2 , there is a tendency to perceive the share of nuclear energy as a burden which almost half of the respondents are ready to accept for mainly economic reasons, whereas the other half would prefer this burden to be replaced by conservation or solar systems. The later group is less willing to sacrifice its antinuclear option as the former group is willing to abandon its nuclear preference. 
This tendency is also clearly indicated by the calculated preference structure that was constructed by multiplying the weights of each criterion with the perceived performance of each scenario and summing up all the products for the eight criteria. According to the calculated results three quarters of all participants gave the highest priority to options 3 and 4 . There is quite a good correspondence between the calculated and the intuitive judgment in the case of scenarios 1 and 3 , but a big gap in the case of scenarios 2 and 4 . In particular, the calculated preference of $37.2 \%$ in favor of scenario 4 strongly contrasts with the intuitive preference of $16 \%$ for this scenario. In the last paragraph of this chapter we will offer some hypothetical explanations for this deviation.

The high degree of ambiguity revealed by this comparison between the two different preference measurements can also be studied by looking at the two components of the calculated index: weights and ratings. We had already shown that the weights themselves do not highly discriminate between the different preferential groups. So we will concentrate our analysis on the ratings.

Table 7 provides an overview of the unweighted ratings (arithmetic means), Table 8 of the weighted ratings (means of weights times ratings). Comparing scenario 2 with 3 it is easy to detect that the antinuclear scenario 3 receives better ratings in four out of eight criteria (environment, health/safety, political effects, and international consequences). Only in one case (security of supply) the pronuclear scenario is regarded as superior. When we take a look at the weighted profiles, the evaluations are more balanced. According to the three economic criteria, option 2 has been associated with slightly higher advantages as opposed to the ratings of option 3. According to the social, political, and international consequences, scenario 3 is still superior compared to scenario 2 . With respect to health/safety and environmental quality, all participants rated the non-nuclear scenarios much more positively than the nuclear ones. Thus the question arises: Why is there a strong tendency towards a positive evaluation of options 3 and 4 , when the intuitive decision turned out to be in favor of option 2, at least for the relative majority? This question can only be answered by investigating the predictive power of our evaluation matrix and the statistical analysis of the resulting errors in prediction.

TABLE 7

Mean Values of the Perceived Performance of the Four Energy Scenarios with Respect to Eight Evaluating Criteria (Unweighted Ratings)

\begin{tabular}{|c|c|c|c|c|c|c|c|c|}
\hline \multirow[b]{3}{*}{ Criterion } & \multicolumn{8}{|c|}{ Scenario Preference } \\
\hline & \multicolumn{2}{|c|}{1} & \multicolumn{2}{|c|}{2} & \multicolumn{2}{|c|}{3} & \multicolumn{2}{|c|}{4} \\
\hline & Mean & Median & Mean & Median & Mean & Median & Mean & Median \\
\hline $\begin{array}{l}\text { Financial and Material } \\
\text { Requirements }\end{array}$ & -0.75 & -1 & 0.25 & 0 & 0.32 & 0 & -0.53 & -1 \\
\hline Security of Supply & -0.2 & 0 & 0.41 & 1 & 0.46 & 1 & 0.12 & 0 \\
\hline Economic Effects & 0.12 & 0 & 0.5 & 1 & 0.29 & 0 & -0.1 & 0 \\
\hline $\begin{array}{l}\text { Environmental } \\
\text { Impacts }\end{array}$ & -1.2 & -1 & -0.5 & -1 & 0.48 & 1 & 1.0 & 1 \\
\hline Health/Safety & -1.0 & -1 & -0.32 & 0 & 0.63 & 1 & 1.2 & 1 \\
\hline Social Impacts & -0.4 & 0 & 0.25 & 0 & 0.35 & 0 & -0.1 & 0 \\
\hline Political Impacts & -0.6 & -1 & -0.1 & 0 & 0.44 & 1 & 0.1 & 0 \\
\hline International Effects & -0.6 & -1 & -0.1 & 0 & 0.45 & 1 & 0.4 & 1 \\
\hline Summed Mean & \multicolumn{2}{|c|}{-0.58} & \multicolumn{2}{|c|}{0.05} & \multicolumn{2}{|c|}{0.43} & \multicolumn{2}{|c|}{0.26} \\
\hline
\end{tabular}


TABLE 8

Mean Values of the Perceived Performance of the Four Energy Scenarios with Respect to Eight Evaluative Criteria (Weighted Ratings)

\begin{tabular}{|c|c|c|c|c|c|c|c|c|}
\hline \multirow[b]{3}{*}{ Criterion } & \multicolumn{8}{|c|}{ Sccnario Preference } \\
\hline & \multicolumn{2}{|c|}{1} & \multicolumn{2}{|c|}{2} & \multicolumn{2}{|c|}{3} & \multicolumn{2}{|c|}{4} \\
\hline & Mean & Median & Mean & Median & Mean & Median & Mean & Median \\
\hline $\begin{array}{l}\text { Financial and Material } \\
\text { Requirements }\end{array}$ & -7.9 & -10 & 4.2 & 10 & 3.7 & 0 & -6.3 & -5 \\
\hline Security of Supply & -3.8 & 0 & 8.3 & 10 & 7.1 & 5 & -0.2 & 0 \\
\hline Economic Effects & 2.2 & 0 & 7.1 & 5 & 2.8 & 0 & -3.1 & 0 \\
\hline $\begin{array}{l}\text { Environmental } \\
\text { Impacts }\end{array}$ & -23.5 & -20 & -9.6 & -10 & 9.2 & 10 & -18.9 & 20 \\
\hline Health/Safety & -22.1 & -20 & -6.1 & 0 & 12.4 & 15 & 22.6 & 20 \\
\hline Social Impacts & -3.2 & 0 & 2.5 & 0 & 5.0 & 0 & -1.2 & 0 \\
\hline Political Impacts & -4.8 & -5 & -0.3 & 0 & 3.3 & 0 & 0.4 & 0 \\
\hline International Effects & -4.6 & -5 & -0.7 & 0 & 2.9 & 0 & 3.0 & 0 \\
\hline Summed Mean & & & & 7 & & & & \\
\hline
\end{tabular}

\section{PREDICTIVE POWER OF THE UTILITY AND FACTOR MODELS}

Before elaborating on the different models of predicting the intuitive judgment with respect to the four energy scenarios it seems worthwhile to have a closer look at the distribution of MAU-scores that characterize the overall performance of the four scenarios. Figure 6 shows the frequency curves for all four scenarios.

There is a clear indication that scenario 1 (highly pronuclear) has been evaluated as inferior compared to the three other options. The more moderate pronuclear scenario 2 has a peak at the zero-point. This supports our impression that option 2 is associated with a high degree of ambiguity. In contrast, scenario 3 has been evaluated much more positively, focusing on two peaks, one at +50 and the other one at +85 . Also the variance of evaluations is smaller compared to scenario 2 . This indicates that scenario 3 has never been rated as totally negative as scenario 2 has been rated occasionally and very rarely as totally positive (which is also true for scenario 2). Scenario 4 (the most proconservation, prosolar, antinuclear scenario) has a particularly interesting shape, because there are two peaks of around equal size, one at the zero-point and one at +50 . If we only consider this distribution of evaluations, we are able to describe more precisely the scoring behavior of the respondents.

If a participant of our seminar evaluated the extreme scenario 4 as ambivalent in its outcomcs, and the sccnario 3 and 2 both positive, he would probably prefer scenario 2 over all other options. If a participant perceived scenarios 3 and 4 as rather positive and scenario 2 as more ambivalent, he would choose scenario 3 when asked for his intuitive preference. An intuitive priority for the two extreme scenarios 1 and 4 was always accompanied by an extreme positive evaluation of the chosen alternative and a clearcut negative perception of the three remaining options. This conclusion can be further reaffirmed when the ranges of the overall evaluations (calculated preferences) are subdivided according to the intuitive preferences. Figure 7 illustrates this relationship.

Most difficult to explain is the scoring behavior of the relative majority preferring the more moderate pronuclear option 2. This group assigns almost equal scores to the scenario 2 and 3 respectively. Also the most antinuclear scenario 4 gains a high degree of appreciation. Participants who had voted in favor of scenario 3 evaluated scenario 4 as at least equally positive. But then why did they decide to give priority to scenario 3 ? 


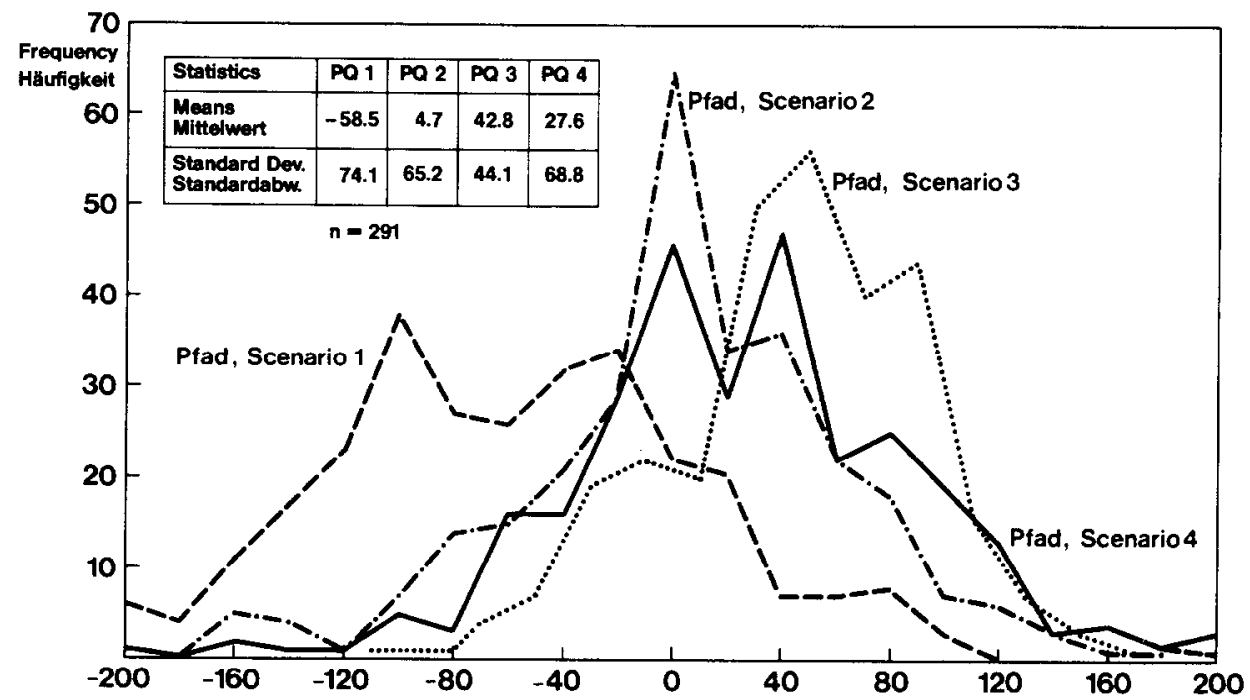

Fig. 6. The frequency distribution of respondents' MAU scores to evaluate the four energy scenarios $($ Pfad $=$ Scenario $)$.

In order to explain the difference between the intuitive and the calculated preferences, it is necessary to compare inconsistencies on an individual level. For this purpose we considered two basic models, one based on the sum of the unweighted ratings for each scenario and the other one based on the sum of the weighted ratings. We performed a cross-tabulation between the intuitive preferences and the model-based calculated preferences. Those preferences were simply derived by choosing the scenario that reached

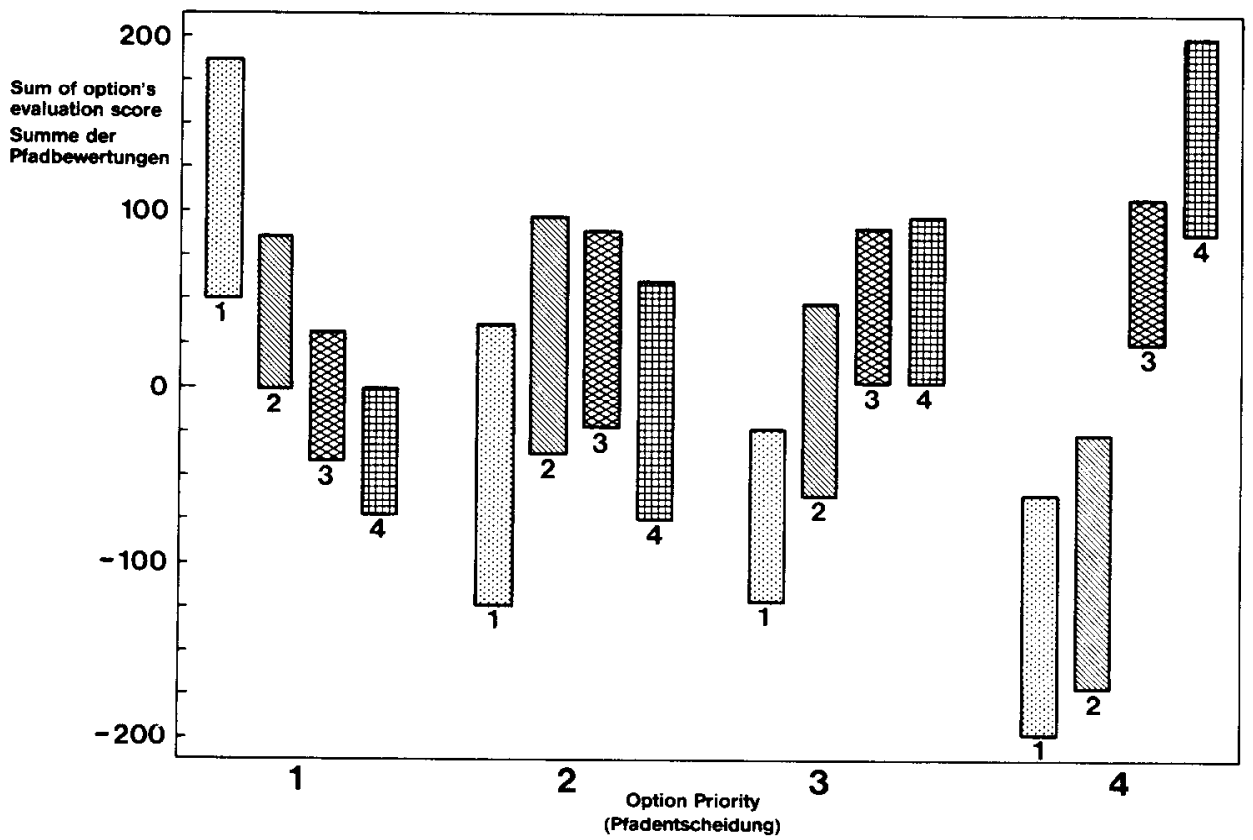

Fig. 7. The ranges of scores for each scenario evaluation as a function of the intuitive preference for one of the four scenarios. 
the highest score on the summed ratings (weighted and unweighted). Figures 8 and 9 illustrate the results of this comparison for both models.

As can be expected from the analysis so far, most errors in prediction occur for the group preferring scenario 2. For both models the proportion of errors is approximately $56 \%$. According to the MAU-model, 25\% belonging to this group scored highest on scenario 3 and the other $25 \%$ on scenario 4 . Looking at the group of respondents who intuitively favored scenario 3 both models, reveals that only a marginal percentage assigned a higher score to options 1 or 2 , but that virtually all errors were due to a calculated preference towards option 4 . The calculated preference is much more likely to be one

\begin{tabular}{|c|c|c|c|c|c|}
\hline \multirow{2}{*}{$\begin{array}{c}\text { Scenario } \\
\text { Priority }\end{array}$} & \multicolumn{4}{|c|}{ Model max. $\left[\sum_{1}^{8}\right.$ ratings $]$} & \multirow{2}{*}{ total } \\
\hline & 1 & 2 & 3 & 4 & \\
\hline 1 & 61.54 & 23.08 & 15.38 & 0 & $\begin{array}{c}13 \\
(=100 \%)\end{array}$ \\
\hline 2 & 6.32 & 44.25 & 29.31 & 20.11 & $\begin{array}{c}174 \\
(=100 \%)\end{array}$ \\
\hline 3 & 1.21 & 4.85 & 57.58 & 36.36 & $\begin{array}{c}165 \\
(=100 \%)\end{array}$ \\
\hline 4 & 1.49 & 2.99 & 44.78 & 50.75 & $\begin{array}{c}67 \\
(=100 \%)\end{array}$ \\
\hline total & 5.25 & 21.48 & 42.48 & 30.79 & $\begin{array}{c}419^{\star} \\
(=100 \%)\end{array}$ \\
\hline
\end{tabular}

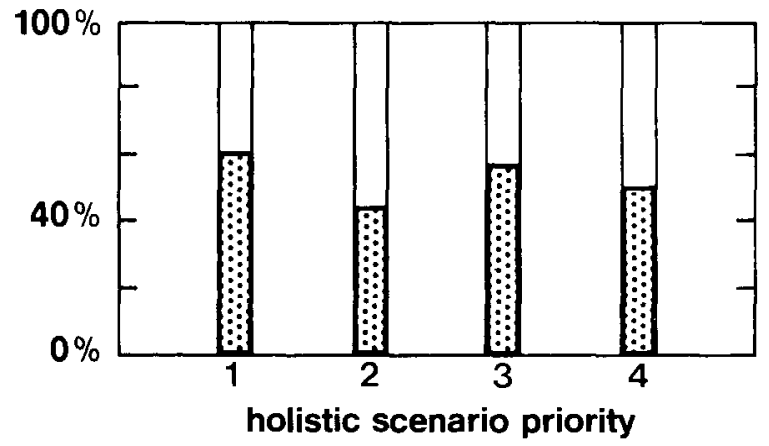

Model:

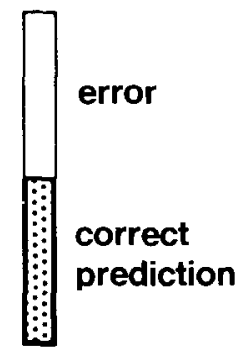

Percentage of correct prediction for the overall model: $\mathbf{5 1 . 0 7} \%$

*replacement of missing data by means

Fig. 8. Contrast between the holistic judgment and the calculated preference via the sum over the multicriteria ratings (unweighted) with respect to the four energy scenarios.* 
step further towards a "softer" scenario, compared to the intuitive preference. If we look at the diagonal line where the perfect fits are described, we can detect hardly any error below that line (meaning that only few participants rated the more nuclear option better on an analytical base than on an intuitive base), but the vast majority of all errors occur above the line.

Another interesting result can be found by looking at the two models. There is little difference between the weighted and unweighted version of the model. The total percentage of correct prediction is $50.13 \%$ for the weighted model and $51.07 \%$ for the unweighted model. We can even detect that the weights bias our model even more towards

\begin{tabular}{|c|c|c|c|c|c|}
\hline $\begin{array}{c}\text { Scenario } \\
\text { Priority }\end{array}$ & \multicolumn{4}{|c|}{ Model max. $\left[\sum_{1}^{8}\right.$ weights x ratings] } & total \\
& 1 & 2 & 3 & 4 & \\
\hline 1 & 53.85 & 38.46 & 7.96 & 0 & $\begin{array}{c}13 \\
(=100 \%)\end{array}$ \\
\hline 2 & 5.75 & 43.86 & 25.86 & 24.71 & $\begin{array}{c}174 \\
(=100 \%)\end{array}$ \\
\hline 3 & 0.61 & 3.64 & 52.12 & 43.64 & $\begin{array}{c}165 \\
(=100 \%)\end{array}$ \\
\hline 4 & 0 & 2.99 & 35.82 & 61.19 & $\begin{array}{c}67 \\
(=100 \%)\end{array}$ \\
\hline total & 4.3 & 21.24 & 37.23 & 37.23 & $\begin{array}{c}419^{\star} \\
(=100 \%)\end{array}$ \\
\hline
\end{tabular}

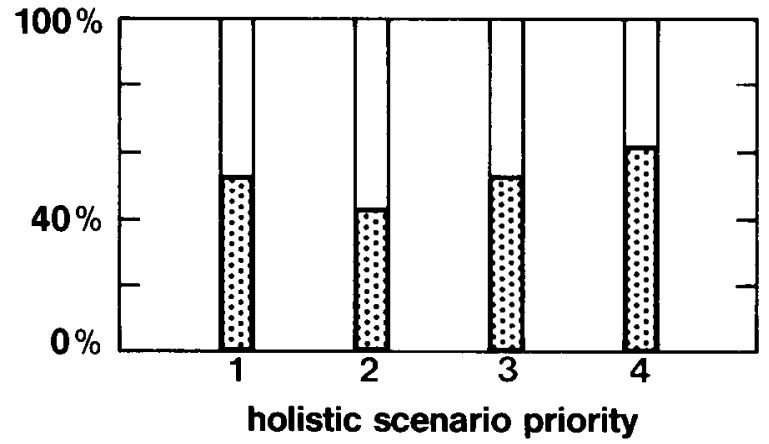

Model:

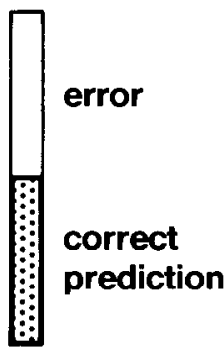

Percentage of correct prediction for the overall model: $50.13 \%$

*replacement of missing data by means

Fig. 9. Contrast between the holistic judgment and the calculated preference via a simplified MAU model (weights times ratings) with respect to four energy scenarios.* 
a soft preference structure. It is clearly reaffirmed, though, that the weights do not play a decisive role in the formation of preferences.

This result appears to be counterintuitive. We had expected that the scaling process based on arguments and rational reasoning would reveal a stronger priority for options 1 and 2, whereas the intuitive judgment influenced by evaluations, visions, and affects would focus on option 3 and 4 . But just the opposite occurred.

What kind of explanations could we find to understand this scoring behavior? First we tried other models to construct a meaningful index of summarizing the ratings of the participants. In order to rule out the strong ties between health/safety and environmental aspects, we combined the ratings for those two criteria into one and based our calculation on a seven-criteria set. But the results did not differ from those of the two original models. Aftr this exercise we used some statistical procedures to construct appropriate models based on multiple regression and factor analysis. Both models did not show any improvement in the percentage of correct prediction. For the purposes of comparison, Figure 10 illustrates the relationships between the intuitive judgment and the calculated results of a factor model. All ratings were multiplied by the factor score coefficient (standing for an indirect measurement of importance for each criterion with regard to the overall intention of all criteria).

Since the factor and the regression models were characterized by the same biases as the previous models, there is little support for the assumption that the discrepancy between the calculated and the intuitive judgment is due to a latent structure of values not overtly expressed by most of the participants. For example, because of social desirability reasons most proponents of scenarios 1 and 2 did not admit that in their view economic values were superior to health and safety. The weights expressed by the advocates of scenarios 3 and 4 , however, came close to the real preference structure of the group. We are still testing the hypothesis of latent value biases by constructing more refined models. But to draw a preliminary conclusion, there is no doubt that the ratings themselves are extremely biased towards a positive evaluation of the scenarios 3 and 4 , and even latent weights assigned to each criterion cannot compensate for this effect.

Of course, there is also the possibility that we had chosen the wrong criteria or we had omitted decisive ones which could be regarded as the underlying causes for the superiority of option 2 in the intuitive rating process. Since we had asked all persons to give explanations for resulting discrepancies between the intuitive and the calculated judgment, we were able to test this hypothesis, at least to the extent that the participants could consciously recall their judgments. Indeed we found some evidence that the list of criteria induced three biases towards scenarios 3 and 4:

1. Many respondents indicated that the three economic criteria (cost, security of supply, and economic consequences) should have more weight for the decisionmaking process, if all three of them received negative evaluations. They thought it would be inadequate to add up the weights for each single economic criterion, but to give extra weight to the joint effect of all threc critcria.

2. Many respondents expressed some objections against the placement of technical feasibility as a subcriterion of the criterion security of supply. They suggested that feasibility should be a separate criterion independent from economic security.

3. Some respondents missed the criterion "Political Implementability." They expressed the opinion that, in particular, option 4 could not be implemented because of pressure group influence. This reason was most frequently expressed by those participants who voted for option 3, but ranked highest on option 4 . 


\begin{tabular}{|c|c|c|c|c|c|}
\hline \multirow{2}{*}{$\begin{array}{c}\text { Scenario } \\
\text { Priority }\end{array}$} & \multicolumn{4}{|c|}{ Model max. [ $\sum_{1}^{8}$ coeff. x ratings] } & total \\
\hline 1 & 1 & 2 & 3 & 4 & \\
\hline 2 & 61.54 & 15.38 & 15.38 & 7.69 & $\begin{array}{c}13 \\
(=100 \%)\end{array}$ \\
\hline 3 & 6.90 & 42.53 & 30.46 & 20.11 & $\begin{array}{c}174 \\
(=100 \%)\end{array}$ \\
\hline 4 & 1.82 & 4.24 & 58.18 & 35.76 & $\begin{array}{c}165 \\
(=100 \%)\end{array}$ \\
\hline total & 5.43 & 19.81 & 43.44 & 31.03 & $\begin{array}{c}67 \\
(=100 \%)\end{array}$ \\
\hline
\end{tabular}

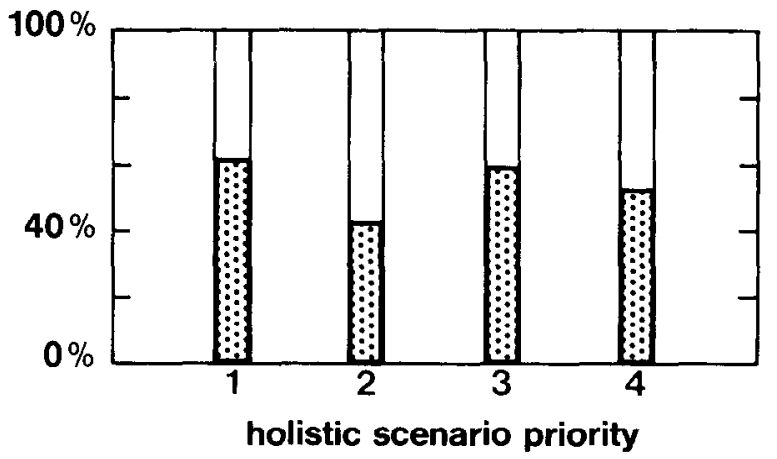

Model:

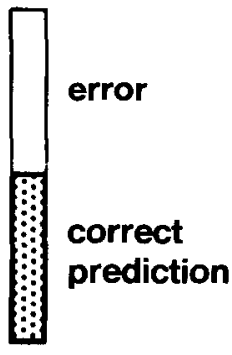

\section{Percentage of correct prediction for the overall model : $\mathbf{5 0 . 8 3} \%$}

\section{*replacement of missing data by means}

Fig. 10. Contrast between the holistic judgment and the calculated preference via factor analysis and the unweighted ratings (factor score coefficients times ratings) with respect to four energy scenarios.*

Apart from these explanations there were only three participants who suggested complete new criteria or modified the criteria list. Some could not give any explanation for the discrepancy.

The most striking result was that during the discussions most of the respondents who had to explain the deviation between intuitive and calculated preference referred to noncognitive reasons. They admitted that most of the arguments would lead to a more favored view of options 3 or 4 , but they trusted the official policy makers in Germany who were believed to have a better inside view on the subject and were thus more competent for this issue. Since most German institutions are in favor of options 1 or 2 , 
TABLE 9

Preference for Energy Scenarios 1 or 2 Versus 3 or 4 as a Function of Age $(n=414)$

\begin{tabular}{cccc}
\hline \multicolumn{3}{c}{ Energy Scenarios } & Energy Scenarios \\
Age & $1 / 2$ & $3 / 4$ & $191(=100 \%)$ \\
$18-40$ & $32.7 \%$ & $67.4 \%$ & $223(=100 \%)$ \\
\hline 41 & $55.2 \%$ & $44.8 \%$ & \\
\hline
\end{tabular}

the participants accepted this judgment and acted accordingly. Reference groups, such as parties, unions, or professional societies, were also cited.

There was no sharp distinction between cognitive and noncognitive explanations. Since most of the respondents gave more than one answer, the criticism of the criteria list and the reference to social group judgments were mixed. However, after reviewing the results we gained the impression that, to a large extent, the cognitive aspects reflected the degree of rationalization of reference group influence.

There are some indications to back up this impression. Figures 11, 12, 13, and Table 9 provide an overview on the distribution of option priorities as a function of sex, age, and party preference. Whereas sex had no impact on the intuitive preference for one of the four options, we detected quite intensive relationships between age, party preference, and option priority. The more conservative people voted in national elections, and the older they were (in particular over 40 years old), the more they preferred options 1 or 2. Older people and conservative voters tend to express more trust in established institutions and assign a higher degree of credibility to politicians and scientists. Indeed we could prove that the majority of the proponents for option 2 having scores higher for option 3 or 4 belonged to the group of conservative and older people. We are still in the process of analyzing the motivational roots of the discrepancies; but right now it already seems justified to conclude that the discrepancies between intuitive and calculated preference is mainly due to loyalty vis-a-vis reference group judgments.

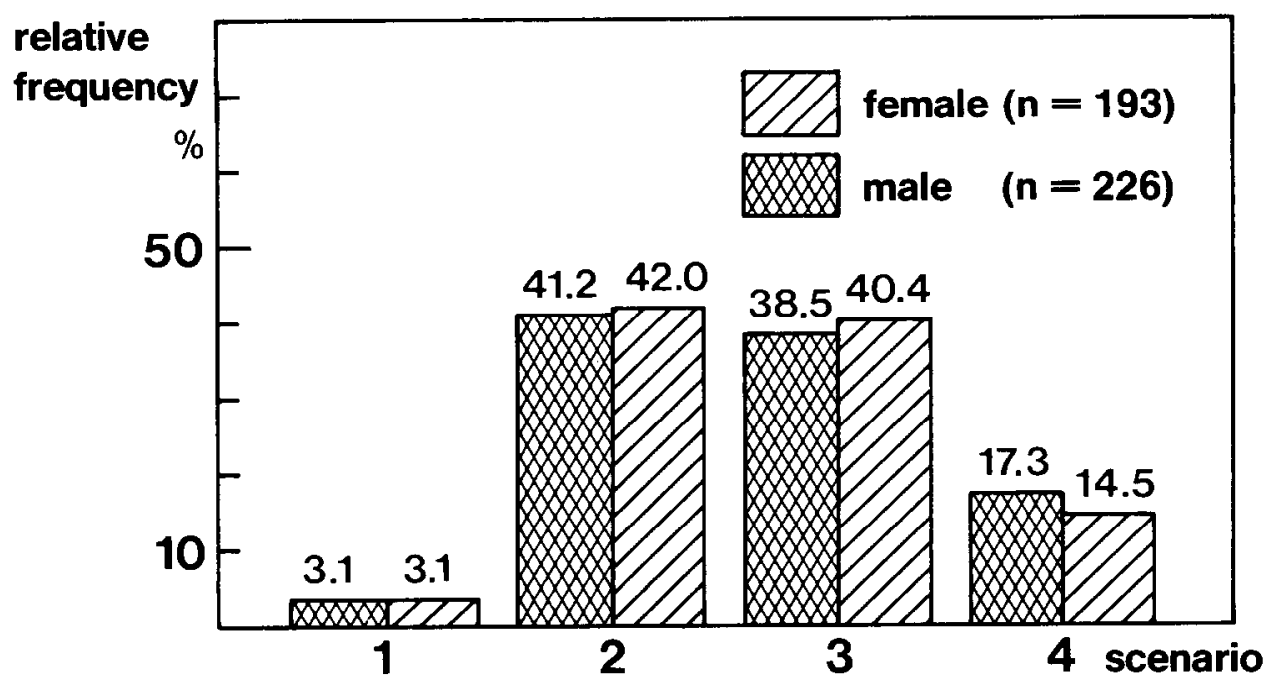

Fig. 11. The preference for one of the four energy scenarios as a function of sex. 


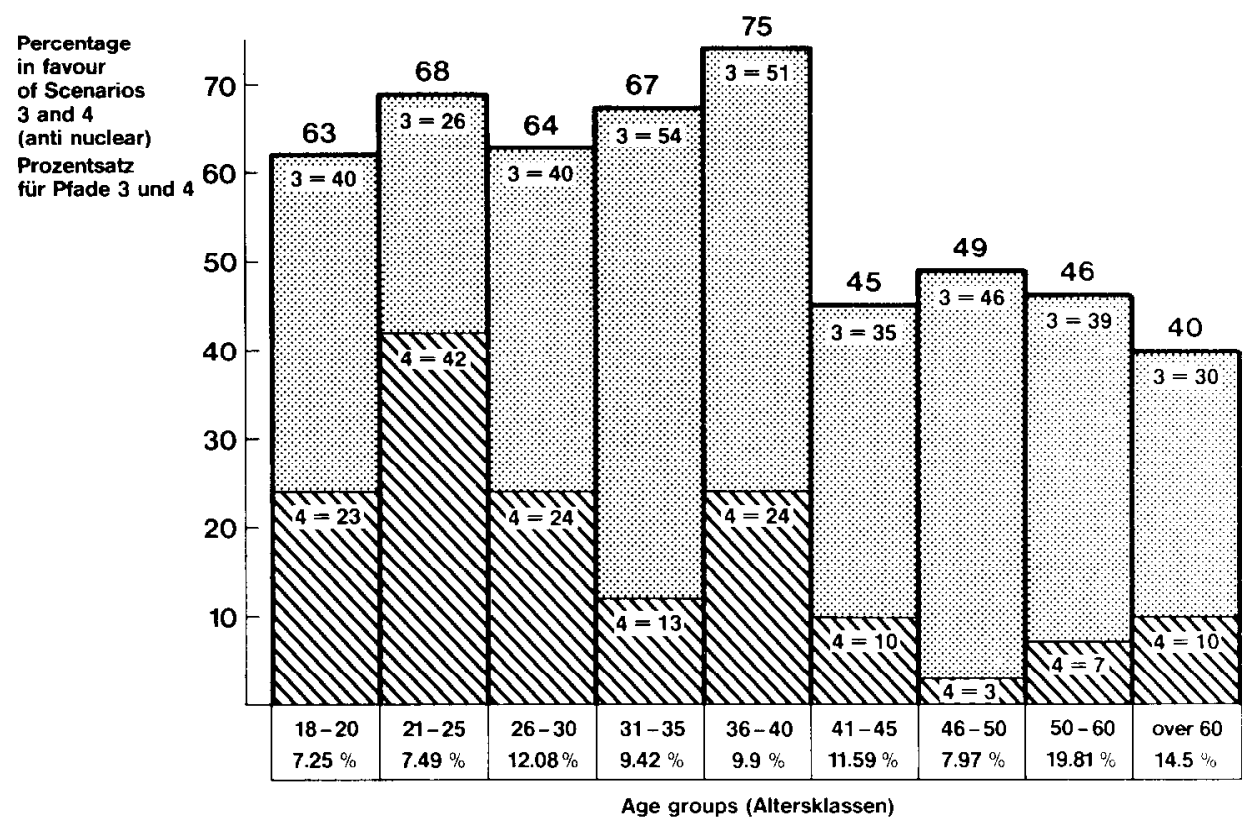

Fig. 12. The preference for one of the four energy scenarios as a function of age.

\section{Conclusions}

The use of planning cells as a participatory element in the political decision-making context turned out to be a highly complex, but rewarding, effort. From the experience with over 20 planning cells we have gained a better understanding of the potentials and the limitations of this model. Also we encountered some difficulties that were not visible when we started our program. The experiences we were able to make justify the further development of the planning cell concept, but revealed at the same time some of the serious problems and drawbacks of picking random samples for policy evaluation. These problems have to be solved before this instrument is used in a wider scope to facilitate decision making under conflict.

The potentials and advantages of the planning cell concept refer to the following purposes:

1. The elicitation of ordinary citizens preferences concerning complex decisions (with input of appropriate information);

2. The understanding of underlying reasons for specific attitudes or beliefs;

3. The measurement of "popularity" or hostility towards proposed governmental policies (after relevant information has been presented);

4. The prediction of opposition against certain objects or policies.

We believe that these four purposes of the planning cell have been fulfilled during our study and could even be improved on if the program is revised once more. Since the participants of planning cells cannot represent the whole population, inferential statistics can only be applied with special care. By comparison with the results of national surveys, there was a good chance of validating common trends and describing more specific results from the planning cell sample. 
Social

Democrats

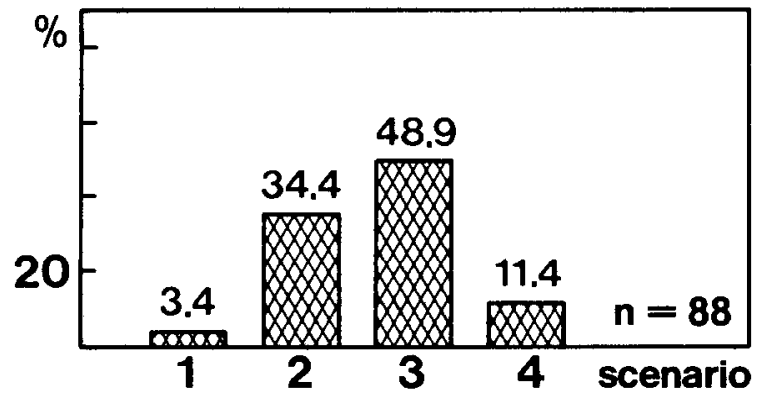

Christian

Democrats

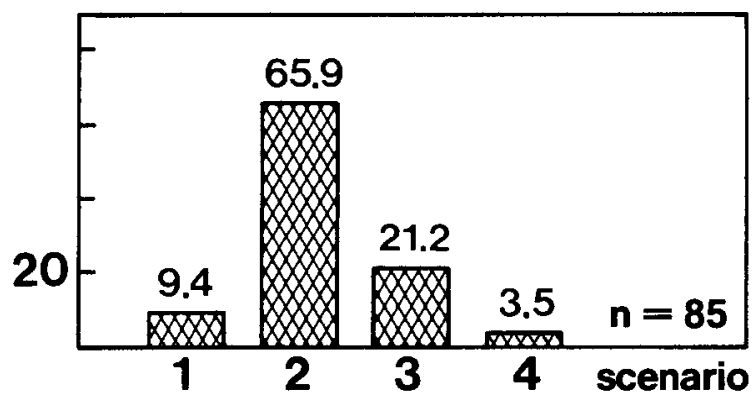

Liberal

Party

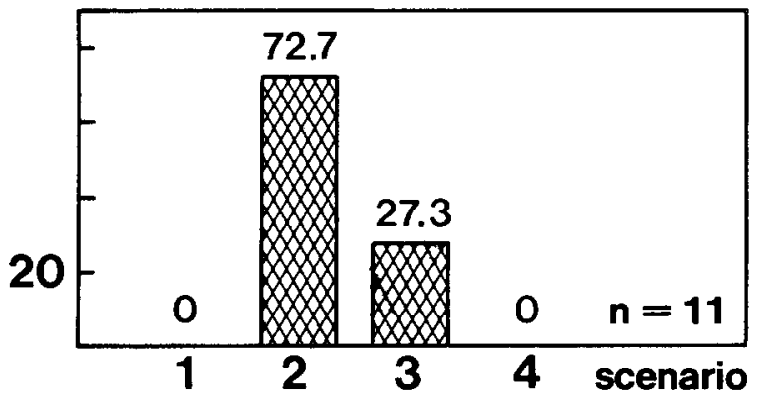

Environmentalist Party

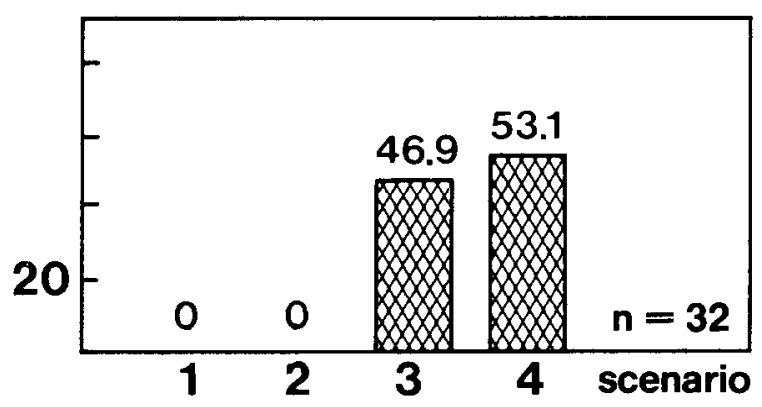

Fig. 13. The preference for one of the four energy scenarios as a function of party preference (hypothetical voting behavior in a national election). 
In contrast to these positive aspects, we faced quite a few limitations which should also be mentioned:

1. The incapability of ordinary citizens to create new or generic solutions to conflict management or resolution;

2. The difficulty in eliciting tradeoffs between different attributes;

3. The problems of aggregating individual weights or ratings and interpreting mean values because of differences between groups, different perceptions of what the weights and rankings mean, response sets, distortions because of social desirability, and other latent factors;

4. The limits of the legitimization effect in polarized disputes (results will be interpreted as manipulated as soon as they deviate from one's own opinion).

Considering these limitations it is evident that planning cells can provide information about the acceptance of objects or policies (after all necessary information is given), but offer little information about the acceptability of objects or policies. To differentiate between acceptance and acceptability reveals at the same time two possible points of interest:

In short, the concept of acceptance means to identify criteria that are empirically considered relevant for evaluating policy options, to assess the potential impacts of these options, and to reveal how these options are evaluated by the society.

The concept of acceptability puts emphasis on studying and evaluating the alternative options in relation to goals, values, and needs, which are considered socially more or less desirable (for a more detailed analysis, see H. Jungermann [4]).

Since our project is mainly directed toward empirically testing the acceptance of energy policies-if all the impacts were known-we obviously had chosen the right instrument, at least when highly complicated national issues are at stake.

Because we contented ourselves with the measurement of acceptable procedures, one question of course immediately comes up: What about participation? Was it not the goal of the whole exercise to introduce public participation into the decision-making process? This question was one of the key problems within the planning cells, also. The participants expressed their discomfort with the double role they had to play. They were consultants and test persons at the same time. If they were regarded merely as a jury to make judgments with respect to given options, we should not be interested in the underlying motives or reasons. If they are regarded as test persons for improving our knowledge on people's preferences, we should not give them the impression of being our "consultants." In order to avoid this conflict we pursued a double strategy: We promised the participants that their expressed preferences were documented and handed over to the Federal Ministry of Research and Technology (Citizens Report) without speculating about motives or underlying reasons. But we also informed them that the policy makers had a viable and legitimate interest in receiving information about why people express special preferences and what kind of values might be involved. This interest can only be met by using survey methods and statistical data processing techniques.

Although this double strategy led to some irritation on the side of the participants, we had the feeling that we succeeded in conveying the purpose for creating such a double role of planning cell participants. The whole procedure reflects our main assumption that participation in complex matters cannot substitute for political decision making. Rather, 
it should be regarded as a decision aid to form and shape political judgments according to the latent and overt value structure of the concerned public. If this assumption is accepted, the planning cell might be the ideal instrument to collect the relevant feedback from society and to reveal the intuitive preferences and values that should be the guidelines of democratic policy-making.

\section{References}

1. Albrecht, G., Stegelmann, H. U. (eds). Energie im Brennpunkt, Zwischenbilanz der Energiedebatte München: High-Tech Verlag (in press).

2. Dienel, P. C. Die Planungszelle. Opladen: Westdeutscher Verlag (1978).

3. Dienel, P. C. New Options for Participatory Democracy. Werkstatt-Papier Nr. 1, Wuppertal (1980).

4. Jungermann, H. The Social Compatibility of Energy Technologies-Theoretical and Fmpirical Approaches in West Germany. in Technology Assessment, Environmental Impact Assessment and Risk Analysis Contributions from the Psychological and Decision Sciences New York: Springer (in press).

5. Renn, O. Wissenschaftliche Politikberatung im Spannungsfeld von Wertwandel und Legitimationskrise. in Perspektiven angewandter Sozialforschung, H. Klages, ed. Opladen: Westdeutscher Verlag (in press).

6. Siebenborn, D. and Nehm, H. Die Planungszelle-eine Form der Bürgerpartizipation. Der Städtetag 7 398-402 (1980).

7. Slovic, P., Fischhoff, B., Lichtenstein, S., and MacGregor, D. Perceived Risk: Psychological Factors and Social Implications. Paper presented at the NATO Advanced Study Institute, Les Arcs, France (August 21-31, 1983) (Manuscript from Decision Research, A Branch of Perceptronics, 1201 Oak Street Eugene. Oregon 97401 , USA).

8. Stillwell, W. G., von Winterfeld, D., and John, R. S. Value Tree Analysis of Energy Supply Alternatives. Technical Report SSR1 81-2, Social Science Research Centre, University of Southem California, Los Angeles (1981); Renn, O. Man, Technology and Risk. Jül-Spez-115, Report of the Nuclear Research Centre, Jülich (1981).

9. von Alemann, U. Partizipation-Demokratisierung-Mitbestimmung (2nd edition). Opladen: Westdeutscher Verlag (1978).

Received 12 December 1983; revised 2 April 1984 